Article

\title{
Hydrostatic Compression Behavior and High-Pressure Stabilized $\beta$-Phase in $\gamma$-Based Titanium Aluminide Intermetallics
}

\author{
Klaus-Dieter Liss ${ }^{1,2,3, *}$, Ken-Ichi Funakoshi ${ }^{4}$, Rian Johannes Dippenaar ${ }^{3}$, Yuji Higo ${ }^{5}$, \\ Ayumi Shiro ${ }^{6, \dagger}{ }^{\text {, Mark Reid }}{ }^{2,3}$, Hiroshi Suzuki ${ }^{1, \ddagger}$, Takahisa Shobu ${ }^{6, \ddagger}$ and Koichi Akita ${ }^{1, \ddagger}$ \\ 1 Quantum Beam Science Center, Japan Atomic Energy Agency, Tokai, Ibaraki 319-1195, Japan; \\ suzuki.hiroshi07@jaea.go.jp (H.S.); akita.koichi@jaea.go.jp (K.A.) \\ 2 Australian Nuclear Science and Technology Organisation, Lucas Heights 2234, Australia; \\ mark.reid@ansto.gov.au \\ 3 School of Mechanical, Materials \& Mechatronic Engineering, Faculty of Engineering and Information \\ Sciences, University of Wollongong, Northfields Avenue, Wollongong 2522, Australia; rian@uow.edu.au \\ 4 Neutron Science and Technology Center, Comprehensive Research Organization for Science and \\ Society (CROSS-Tokai), Tokai, Ibaraki 319-1106, Japan; k_funakoshi@cross.or.jp \\ 5 SPring-8, Japan Synchrotron Radiation Research Institute, Kouto, Sayo, Hyogo 679-5198, Japan; \\ higo@spring8.or.jp \\ 6 Quantum Beam Science Center, Japan Atomic Energy Agency, Kouto, Sayo, Hyogo 679-5148, Japan; \\ shiro.ayumi@qst.go.jp (A.S.); shobu@sp8sun.spring8.or.jp (T.S.) \\ * Correspondence: kdl@ansto.gov.au or liss@kdliss.de; Tel.: +61-2-9717-9479 \\ + Present Address: Quantum Beam Science Research Directorate, National Institute for Quantum and \\ Radiological Science and Technology, Kouto, Sayo, Hyogo 679-5148, Japan. \\ $\ddagger \quad$ Present Address: Materials Sciences Research Center, Japan Atomic Energy Agency, Tokai, Ibaraki 319-1195, \\ Japan and Kouto, Sayo, Hyogo 679-5148, Japan.
}

Academic Editor: Hugo F. Lopez

Received: 15 April 2016; Accepted: 13 June 2016; Published: 15 July 2016

\begin{abstract}
Titanium aluminides find application in modern light-weight, high-temperature turbines, such as aircraft engines, but suffer from poor plasticity during manufacturing and processing. Huge forging presses enable materials processing in the 10-GPa range, and hence, it is necessary to investigate the phase diagrams of candidate materials under these extreme conditions. Here, we report on an in situ synchrotron X-ray diffraction study in a large-volume press of a modern $\left(\alpha_{2}+\gamma\right)$ two-phase material, Ti-45Al-7.5Nb-0.25C, under pressures up to 9.6 GPa and temperatures up to $1686 \mathrm{~K}$. At room temperature, the volume response to pressure is accommodated by the transformation $\gamma \rightarrow \alpha_{2}$, rather than volumetric strain, expressed by the apparently high bulk moduli of both constituent phases. Crystallographic aspects, specifically lattice strain and atomic order, are discussed in detail. It is interesting to note that this transformation takes place despite an increase in atomic volume, which is due to the high ordering energy of $\gamma$. Upon heating under high pressure, both the eutectoid and $\gamma$-solvus transition temperatures are elevated, and a third, cubic $\beta$-phase is stabilized above $1350 \mathrm{~K}$. Earlier research has shown that this $\beta$-phase is very ductile during plastic deformation, essential in near-conventional forging processes. Here, we were able to identify an ideal processing window for near-conventional forging, while the presence of the detrimental $\beta$-phase is not present under operating conditions. Novel processing routes can be defined from these findings.
\end{abstract}

Keywords: high pressure; high temperature; phase transformation; equation of states; plasticity; TiAl; intermetallics; synchrotron radiation; multi-anvil press; in situ diffraction 


\section{Introduction}

Titanium aluminides exhibit significant potential as a low specific weight structural material for high-temperature automotive and aerospace propulsive applications [1-4]. Gamma-based TiAl intermetallics possess high strength and excellent oxidation resistance at half the specific weight of conventionally-employed nickel-based superalloys, up to a temperature range of 1000-1100 K [5]. The drawback, however, of the two-phase $\left(\gamma+\alpha / \alpha_{2}\right)$ material is the poor ductility, reduced forgeability and a small deformation window for thermo-mechanical processing [3]. To overcome these limitations, material-design focuses on $\beta$-solidifying alloys, which are characterized by the presence of a ductile $\beta / \beta_{0}$-phase at the processing temperature. However, through appropriate heat treatments, this ductile phase can be transformed to mechanically-stronger structures at the expected operating temperatures [6]. In addition, heating into a multi-phase field results in sluggish grain growth, while the augmented fraction of $\beta$-phase allows for near-conventional forging [7]. This has been partly achieved by alloying $\gamma$-based TiAl alloys with $\beta$-stabilizing elements, such as $\mathrm{Nb}$ and Mo; however, some residual $\beta / \beta_{0}$-phase is still present at the operating temperature $[4,8-10]$.

In the present study, we investigate the influence of pressure on the formation of the ductile $\beta$-phase in $\gamma$-based TiAl alloys, which is not only of fundamental interest, but is also most relevant to modelling high-pressure deformation techniques, such as high-pressure torsion, in order to achieve severe plastic deformation [11-15] and high-pressure near-net-shape forging [16-19]. These deformation processes operate at pressures up to $7 \mathrm{GPa}$ and forces exceeding $1 \mathrm{GN}$, respectively. However, to date, no experimental studies have been reported of the attempts to assess the high-pressure performance of this two-phase $\left(\gamma+\alpha_{2}\right)$ TiAl intermetallic, and very little has been done from a theoretical point of view [20]. Examinations of the pure-titanium temperature-pressure phase diagram [21,22] reveal that pressure-dependent phase transformations can be expected to occur, but the exact intermetallic chemistry and the multi-phase fields in the TiAl alloy system can significantly modify these trends.

In the binary, $\gamma$-based titanium aluminide alloy system, an ordered, close-packed and not necessarily stoichiometric $h c p$-based $\alpha_{2} \mathrm{Ti}_{3} \mathrm{Al}$ co-exists with the tetragonal $\gamma$-TiAl-phase, which is an ordered, close-packed structure, derived from the $f c c$ lattice. The $\alpha_{2}$-phase disorders to $h c p$ $\alpha$ at the eutectoid temperature $T_{\text {eu }}$ and $\gamma$ fully transforms into $\alpha$ at the $\gamma$-solvus temperature $T_{\gamma \text {,solv, }}$ also referred to as $\alpha$-transus temperature $T_{\alpha}$. This high-temperature single-phase field is prone to excessive grain growth and, on deformation, inherits the anisotropic plastic behavior from the hexagonal lattice $[8,23,24]$. A variety of alloys based on TiAl with additions of niobium has been developed in the so-called TNB alloy series [5,25-27], where Nb substitutes Ti sites and eventually stabilizes the $b c c$-based $\beta$-phases. In the present study, we have investigated the TNB composition Ti-45Al-7.5Nb-0.25C, which has been produced through a powder-metallurgical route by Gerling et al. [28] using gas-atomization and subsequent hot-isostatic pressing for $2 \mathrm{~h}$ at $200 \mathrm{MPa}$ and $1553 \mathrm{~K}$. It is obtained from the same series as extensively characterized by Chladil et al. [29,30] and Yeoh et al. [31], showing globular $\gamma-\mathrm{TiAl} / \alpha_{2}-\mathrm{Ti}_{3} \mathrm{Al}$ grains with an average size of about $15 \mu \mathrm{m}$ (see Figure $1 b$ in [29]). In situ investigations revealed conventional transformation behavior for this Ti-45Al-7.5Nb-0.25C alloy, with $T_{\mathrm{eu}}=1453 \mathrm{~K}$ and $T_{\alpha}=1565 \mathrm{~K}$, with an additional peritectic $(\alpha+\beta)$-phase field at $T_{\text {per }} \sim 1500 \mathrm{~K}$, but no $(\alpha+\beta+\gamma)$-phase field has been observed.

The pure-titanium temperature-pressure phase diagram has been well investigated $[21,32]$. At atmospheric pressure and $T_{\beta}(0)=1155 \mathrm{~K}, h c p \alpha$-Ti transforms into $b c c \beta$-Ti. Under hydrostatic pressure, the $\beta$-transus temperature $T_{\beta}$ decreases linearly to meet the triple-point with the hexagonal $\omega$-phase, at about $940 \mathrm{~K}$ and $9.0 \mathrm{GPa}$. Above this pressure, $T_{\beta}$ increases again. The authors also reported that at and above room temperature, the $\omega$-phase occurs only at higher pressure, appearing above $2 \mathrm{GPa}$. Aluminium, on the other hand, behaves as a simple solid, not transforming from its $f_{c c}$ structure under high pressure [33].

It is not possible to predict the behavior of intermetallic titanium aluminide alloys by using the pure-titanium temperature-pressure phase diagram. However, indications are that phase boundaries 
can shift with applied pressure and that the $\beta$-phase can be stabilized because the $\beta$-transus line has a negative slope. Moreover, there is a distinct likelihood that changes in lattice parameters and modified atomic packings, including atomic order and disorder, might influence the phase relationships.

In order to study the phase changes in TiAl intermetallic systems, in situ quantum beam diffraction [34], such as X-rays and neutrons, has been employed. The first in situ X-ray diffraction studies on these intermetallics have been undertaken by Shull and Cline [35], but the real breakthrough came when Liss et al. [36] used high-energy synchrotron radiation [37], to study these alloys. Combined time-resolved and multi-dimensional diffraction in a so-called materials oscilloscope [38] allows determination of the microstructural evolution of multi-phase titanium aluminides during thermo-mechanical processing [7,39]. In situ neutron diffraction is complementary to X-ray studies, due to the negative and positive scattering lengths of $\mathrm{Ti}$ and $\mathrm{Al}$, respectively, and is therefore ultimately sensitive to the atomic order in a crystal structure $[40,41]$.

High-pressure diffraction equipment has been well established for a number of decades at synchrotron radiation facilities, mainly driven by the geoscience community, but its application to structural materials science is still in its infancy [42,43]. The most common pressure device is a diamond-anvil cell, capable of reaching pressures up to $200 \mathrm{GPa}$ and temperatures up to $5000 \mathrm{~K}$ [44]; however, with a maximum diameter of $\sim 0.2 \mathrm{~mm}$, the total volume of samples is limited. On the other hand, large-volume multi-anvil cells can be used for samples up to an 8-mm side length, with compromises on the maximum achievable pressure of up to approximately 30-50 GPa [45,46], but more typically in the 10-GPa range. Heating can be achieved by building furnaces into the hydrostatic volume, resulting in available sample volumes of $1-2 \mathrm{~mm}^{3}$.

Because excessive grain growth in titanium alloys becomes a serious problem at very high temperature, a powder diffraction experiment might degenerate into a study of single crystals if the experimentally-accessible reciprocal space volume is collimated [47]. Moreover, studies of microstructural evolution, allowing for the segregation of the elements in a multi-phase field, such as the co-existing $\gamma$ and $\alpha_{2}$-phases in titanium aluminides, require larger sample volumes. Furthermore, the chemistry of titanium alloys may change at the surface layer, such as the depletion of aluminium, as observed in a vacuum [40] or influenced by the pressure medium, as well as uni-axial stress components [48].

\section{Experimental Section}

In the current study, diamond anvil cells were deemed unsuitable, and large-volume multi-anvil cells have been utilized in order to ensure that a sufficiently large volume is available to allow for microstructural evolution and segregation. More specifically, the 15-MN force, Kawai-type multi-anvil machine, SPEED-Mk. II, at the SPring- 8 bending magnet beamline BL04B1 was utilized. The beamline setup is depicted in Figure 1 [49], and a detailed description of the pressure apparatus was given by Katsura et al. [50]. A 10 mm-thick germanium solid-state detector of CANBERRA industries has been employed for energy-dispersive diffraction at a horizontal take-off angle of $2 \theta=5.9827^{\circ}$. While the detector records energies from $3 \mathrm{keV}$ onwards, the spectrum transmitted through the pressure cell ranges from $\sim 34-140 \mathrm{keV}$, thereby covering a diffractogram from $\sim 1.8-7.5 \AA^{-1}$, as shown in Figure 2 . Energy calibration of the detector was done by recording the fluorescence lines of $\mathrm{Mo}, \mathrm{Pb}, \mathrm{Au}, \mathrm{Ag}$, $\mathrm{Pt}, \mathrm{Ta}$ and $\mathrm{Cu}$, before the cell was put into position. In addition to the main detector, a radiography setup was used, implemented by a YAG scintillator (Hamamatsu Photonics K.K., Hamamatsu, Japan), projected to a CCD camera. It images the transmitted beam through the pressure cell and allows for the control of the beam size via a slit system to focus on the sample or the pressure marker. Typical radiographs are shown in Figure 3. In order to reduce the effect of grain size on intensity readings, the whole SPEED-Mk.II apparatus (Sumitomo Heavy Industries, Ltd., Tokyo, Japan), containing the load frame and the pressure cell with the sample, has been oscillated during data acquisition by $8^{\circ}$, which is an important feature of the instrument used [50].

The heating pressure cell was designed and fabricated by the experimental team, and the details of the design are shown in Figure 4. It consists essentially of a sample space and a pressure marker of a $60 \mathrm{MgO}-40 \mathrm{Au}$ (mass \%) mixture, located in $\mathrm{LaCrO}_{3}$ resistive furnace, contacted by platinum leads 
and controlled by an alternate-current power supply. A W-type thermo-couple of W-3Re and W-25Re (mass \%) was used for temperature measurements. The remaining space is filled with insulating and pressure propagating ceramics, such as $\mathrm{ZrO}_{2}, \mathrm{BN}$ and $\mathrm{MgO}$. The furnace assembly sits in a 4.5-mm bore of the pressure octahedron, made of semi-sintered $\mathrm{MgO}-5 \mathrm{Cr}_{2} \mathrm{O}_{3}$ (mass \%), which is then installed into the two-stage multi-anvil press (Figure 5). The gasket material is pyrophyllite.

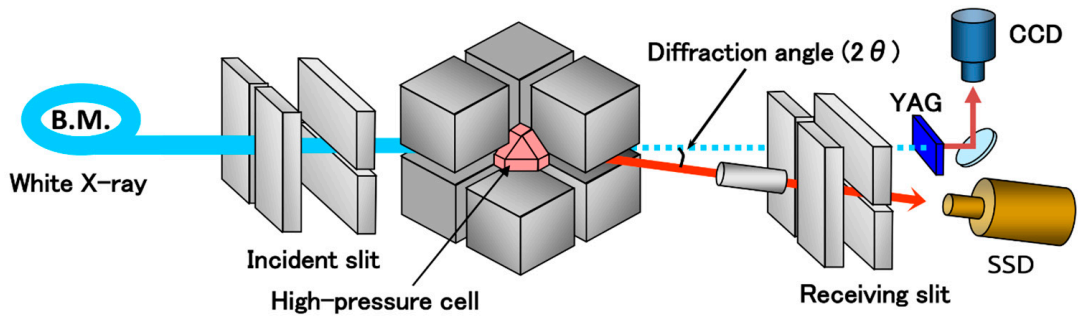

Figure 1. Schematic layout of the beamline. White X-rays emit from the bending magnet (B.M.), which are conditioned by incident slits to enter the high-pressure cell. Transmitted X-rays are used to image the sample cell, converted by a scintillator, YAG, and recorded by a camera, CCD. A fixed diffraction angle, $2 \theta$, is selected by a collimator and receiving slits in front of the solid state X-ray detector, SSD. After [49].

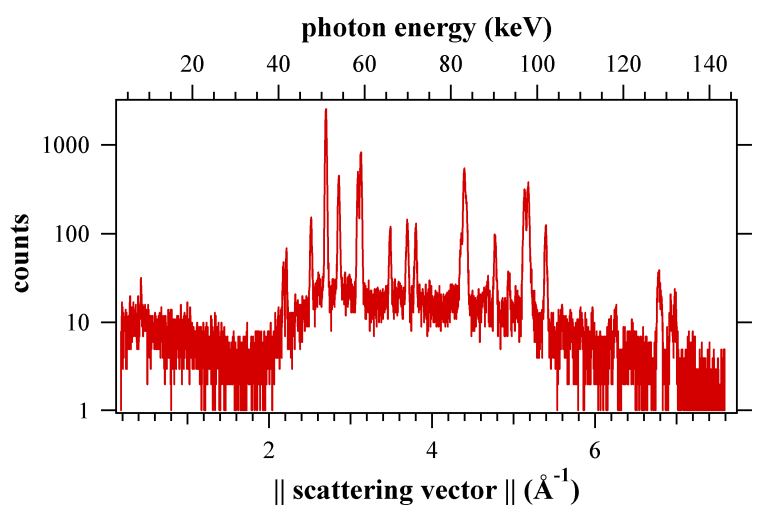

Figure 2. Full recorded detector spectrum (top axis), translating into a calibrated diffractogram (bottom axis). The bump in the background denotes the useful, transmitted energy spectrum between $\sim 34$ and $140 \mathrm{keV}$, i.e., $\sim 1.8-7.5 \AA^{-1}$. The data shown are the signals off the specimen at $310 \mathrm{~K}$ and $0 \mathrm{GPa}$.
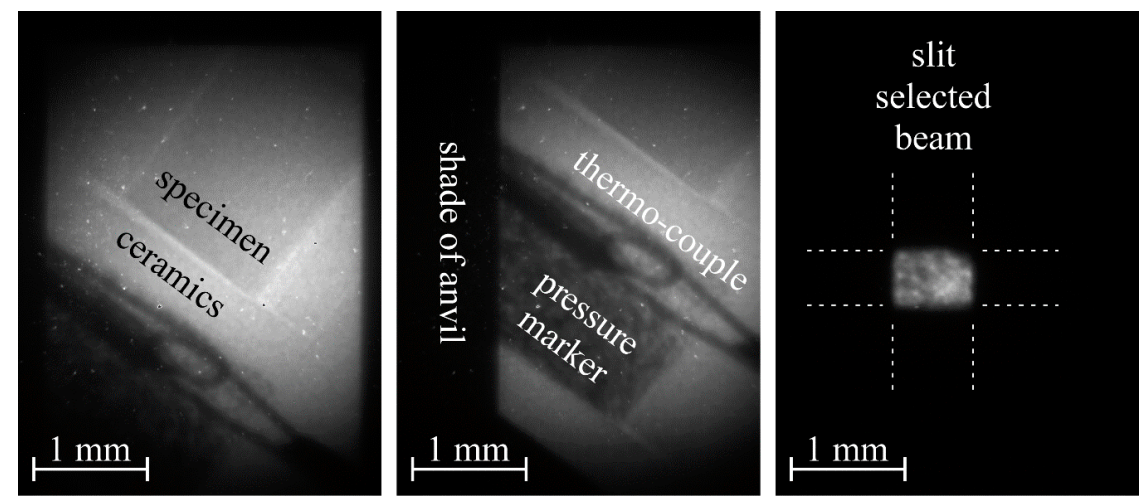

Figure 3. Typical radiographies of the pressure cell for sample alignment. The horizontal and vertical instrument axes show up and right in the figure. Translation of the entire apparatus with respect to the beam allows for different fields of view. The looped thermo-couple is a feature that can be well recognized in the left and central picture. To the right, beam size has been reduced to focus on a particular volume only, here the pressure marker. 


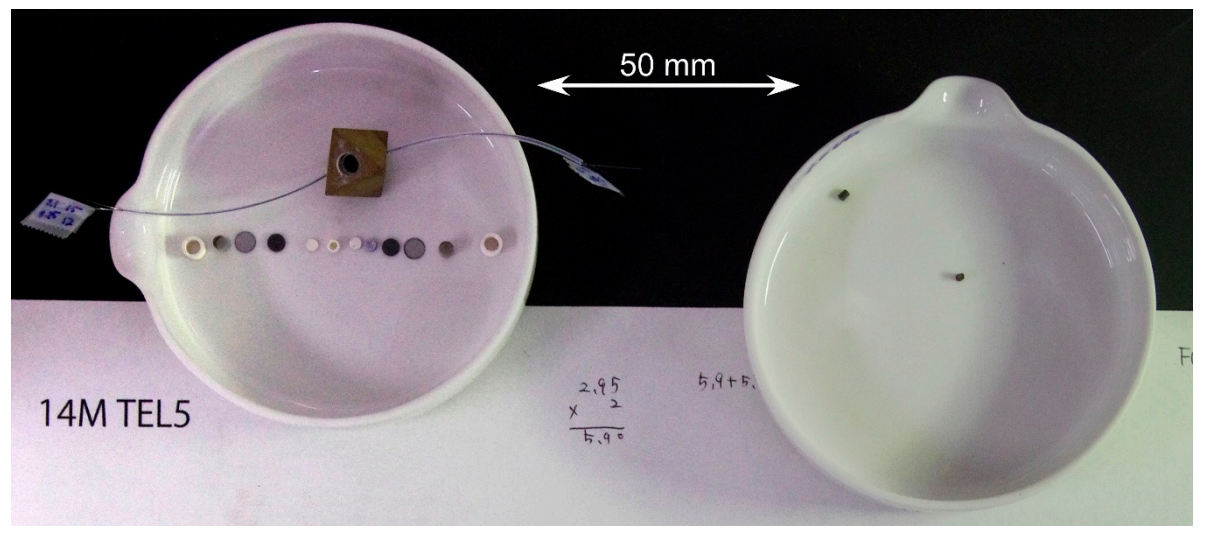

(a)

\section{M TEL5}

(b)

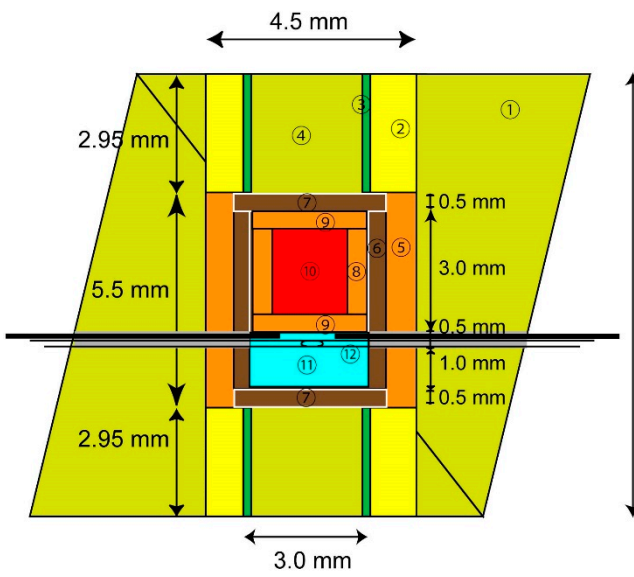

(1) Octahedron(14M TEL5)

(2) $\mathrm{ZrO} 2$ sleeve $\phi 4.5 \times \phi 3.0 \times 2.95 \mathrm{t} \mathrm{mm}$

(3) Pt tube $\phi 3.0 \times \phi 2.8 \times 2.95 \mathrm{tmm}$

(4) $\mathrm{MgO}$ rod $\phi 2.7 \times 2.95 \mathrm{tmm}$

(5) BN sleeve $\phi 4.5 \times \phi 3.5 \times 5.5 \mathrm{t} \mathrm{mm}$

(6) Graphite heater $\phi 3.5 \times \phi 2.5 \times 4.5 \mathrm{tmm}$

(7) Graphite cap $\phi 3.5 \times 0.5 \mathrm{t} \mathrm{mm}$

(8) BN sleeve $\phi 2.5 \times \phi 1.5 \times 2.0 \mathrm{t} \mathrm{mm}$

(9) BN cap $\phi 2.5 \times 0.5 \mathrm{t} \mathrm{mm}$

(10) Sample $\phi 1.5 \times 2.0 \mathrm{t} \mathrm{mm}$

(11) Pressure marker $\phi 2.5 \times 1.5 \mathrm{t} \mathrm{mm}$
(MgO+Au (3:2wt\%) powder)

(12) W/Re thermocouple $\phi 0.1 \mathrm{~mm}+\phi 0.25 \mathrm{~mm}$

Figure 4. Design of pressure cell 14 M TEL5 (b) and photograph of the individual parts (a, left dish) and specimens (a, right dish).

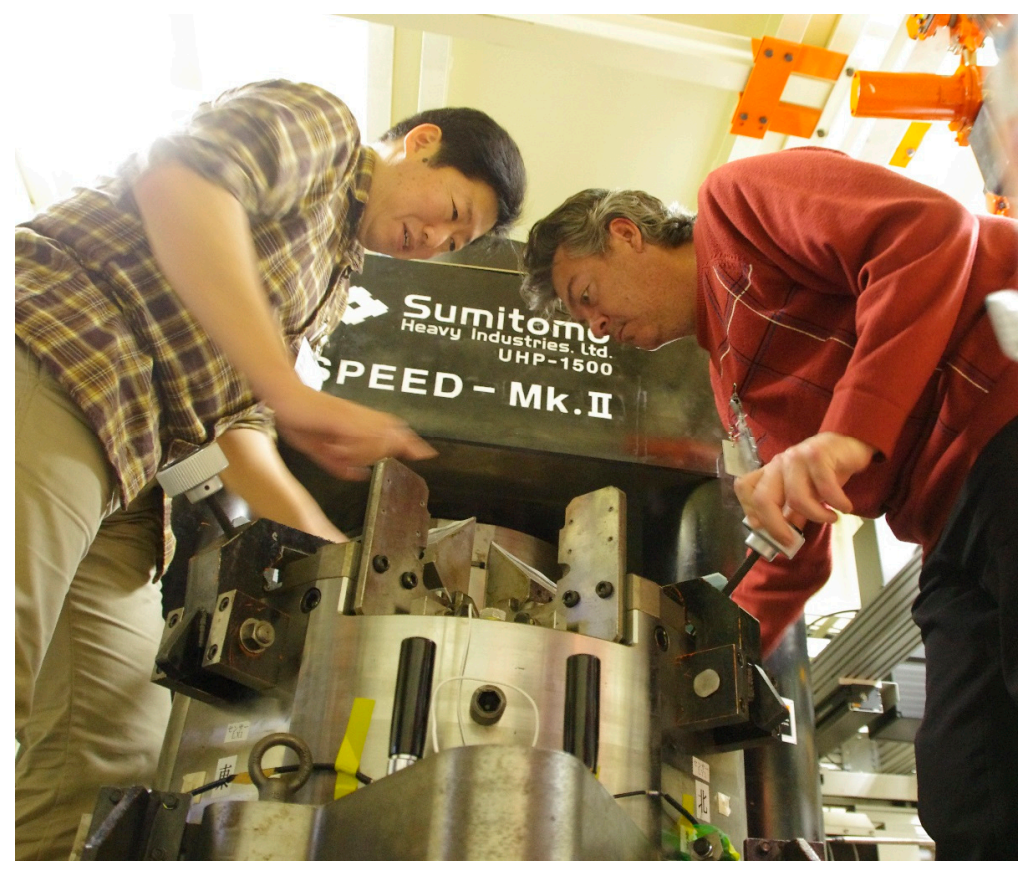

Figure 5. Ken-ichi Funakoshi and Mark Reid loading the pressure cell and sample into the 15-MN press SPEED-Mk.II at SPring-8 beamline BL04B1. 
The serial number of the experimental dataset is M1472. Radiographs were taken to locate the sample and the pressure marker positions and to achieve an optimal beam size of $0.5 \times 0.7 \mathrm{~mm}^{2}(h \times v)$; see Figure 3. Initially, the pressure was ramped stepwise to a target of $10 \mathrm{GPa}$, while the pressure was accurately determined by the use of the equation of state of the pressure markers [51,52], using the PDIndexer software (V4.32, Yusuke Seto, Kobe University, Kobe, Japan, 2016) [53]. Diffraction patterns were taken while holding at 0,3.2 and 9.6 GPa, respectively, before the system was heated under maximum pressure.

The measured photon energy $E$ is correlated with the wave number $k=2 \pi E / h c ; k\left(\AA^{-1}\right)=0.506768$ $E(\mathrm{keV})$, where $h$ denotes the Planck constant and $c$ the speed of light. With Bragg's relation $q=2 k$ $\sin (\theta)$, this translates to the scale of momentum transfer or scattering vector in reciprocal space $q$. In the present case, the calibration is $q\left(\AA^{-1}\right)=5.2892 \cdot 10^{-2} E(\mathrm{keV})$.

Figure 6 displays the expanded diffractograms, taken at room temperature during pressurizing pressure steps, while Figure 7 shows all of the data in a zoomed range, both at room temperature and upon heating. A Rietveld refinement, using the MAUD program [54], was utilized for the analysis, allowing for the extraction of lattice parameters and phase fractions.

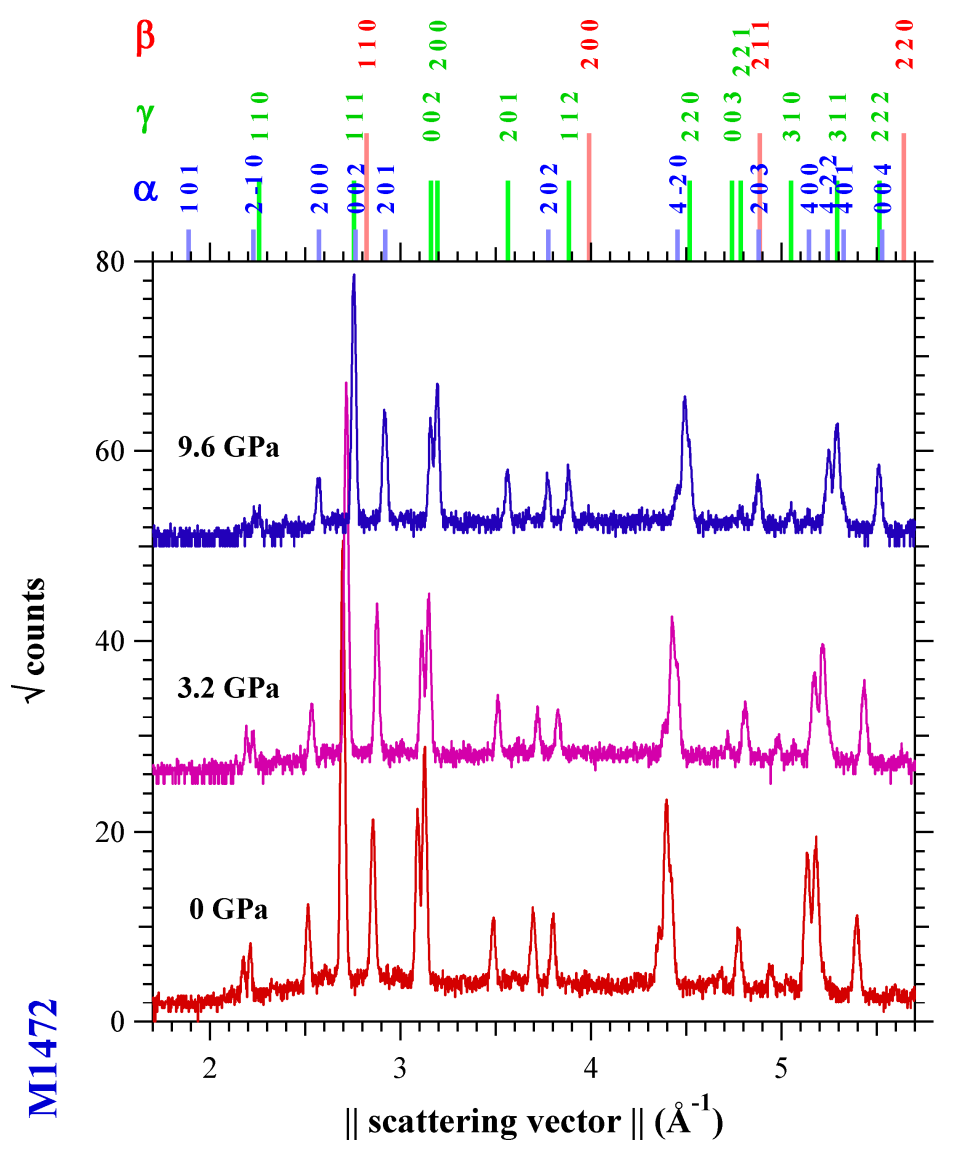

Figure 6. Diffraction patterns upon pressurizing. Line shifts to larger scattering vectors can be seen as the unit cell shrinks, accompanied by changes of peak intensity due to phase transformation.

Unless otherwise stated, we used the following choice of unit cell throughout the paper: both $\alpha$-and $\alpha_{2}$-phases $\left(\alpha / \alpha_{2}\right)$ span a hexagonal lattice with the $a$-axis being twice and $c$ equal to those of conventional hcp. $\alpha_{2}$ and $\alpha$ differ by an ordered and disordered motif, respectively, the former making up the stoichiometry $\mathrm{Ti}_{3} \mathrm{Al}$. In order to compare the axis ratios, $2 c / a$ is listed for the $\alpha-/ \alpha_{2}$-phases, which directly compares to $c / a$ of a simple $h c p$ structure, in its ideal, close-packed case where $c / a_{h c p}=\sqrt{8 / 3}=1.6329932$. The $\gamma$-lattice is constructed from the $f c c$ structure by altering the Ti and $\mathrm{Al}$ 
layers along the $c$-direction. The unit cell is therefore tetragonal and slightly distorted, with a $c / a$ ratio slightly larger than 1 . The cubic $\beta$-phase is either disordered and $b c c$ or ordered $\beta_{\mathrm{o}}$ of Strukturbericht designation B2, where the two different kinds of atom sit on the corner and the body center of the cube. Accordingly, the unit cell volumes are $V_{Z, \alpha}=\sqrt{3} / 2 \cdot a^{2} c, V_{Z, \beta}=a^{3}$ and $V_{Z, \gamma}=a^{2} c$. It is of interest to calculate the volume per atom $V_{\mathrm{A}}$ by dividing these volumes by the number of atoms in the unit cell, i.e., 8,2 and 4 , respectively, leading to $V_{A, \alpha}=\sqrt{3} / 16 \cdot a^{2} c, V_{A, \beta}=1 / 2 \cdot a^{3}$ and $V_{A, \gamma}=1 / 4 \cdot a^{2} c$.

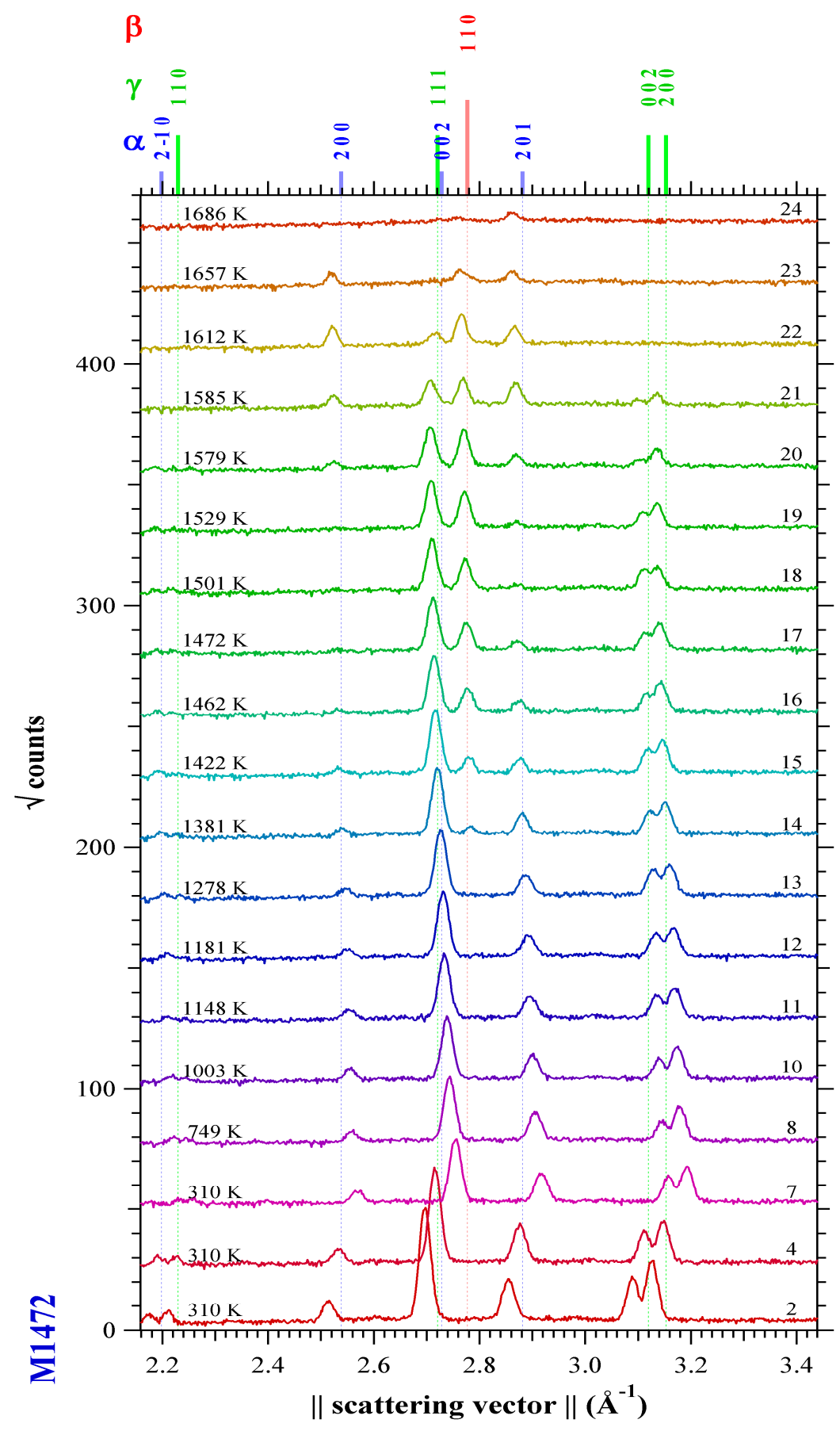

Figure 7. Zoomed compilation of all diffraction patterns upon pressurizing at room temperature (first 3) and on stepwise temperature ramping at the maximal achieved pressure. Temperature tags are given to the left, serial numbers to the right. 


\section{Results and Discussion}

The large diffraction peak around $2.7 \AA^{-1}$ in Figure 6 corresponds to the close-packed plane-stacking distance and is therefore common to both the $f c c$-based $\gamma$ - and $h c p$-based $\alpha$ - $/ \alpha_{2}$-phases, indexing 111 and 002, respectively (there is a small irresolvable shift between the two, due to slight deviation from close-packing in each phase). Only $\alpha_{2}$ and $\gamma$ peaks can be identified at room temperature, while $\beta$ peaks appear at $1381 \mathrm{~K}$ and increase in intensity above that temperature. The $\beta-110$ peak lies around $2.75 \AA^{-1}$, representing a near close-packed lattice spacing. The typical $f_{c c}$ peak positions of the $\gamma$-phase are split, due to the tetragonal deformation with an axes ratio $c / a>1$, by only a few percent. Both the $\gamma$ - and $\alpha_{2}$-phases show superstructure reflections due to atomic order at room temperature, i.e., reflections, which would have vanishing structure factors in fully-disordered lattices, $f_{c c}$ and $h c p$ in the present case.

\subsection{Pressure Loading at Room Temperature}

Pressure loading at room temperature has been evaluated at $\{0,3.2,9.6\} \mathrm{GPa}$ and leads to continuous peak shifts to larger scattering vectors due to the compressive strain on the unit cell. Furthermore, the splitting of the $\gamma-002 / 200$ and $\gamma-112 / 211$ peaks around $\sim 3.1 \AA^{-1}$ and $\sim 5.2 \AA^{-1}$, respectively, diminishes slightly, resulting in a decreasing $c / a$ ratio. Furthermore, relative changes in peak intensity are observed throughout the pressurization process. The volumetric strain allows the evaluation of the equation of state in this two-phase system.

\subsubsection{Crystallographic Anisotropy, Disorder and Transformation Behavior}

Linear lattice strain $\varepsilon$, for a given reflection at position $G=G_{h k l}$ and Miller indices $h, k, l$, is evaluated in reciprocal space by:

$$
\varepsilon=\varepsilon_{h k l}=-\frac{\Delta G}{G_{0}}=\frac{G_{0}-G}{G_{0}}
$$

where $G$ and $G_{0}$ are the strained and unstrained reciprocal lattice vectors, respectively. Here, we select the values of $G_{0}$ at ambient conditions ( $310 \mathrm{~K}, 0 \mathrm{GPa}$ ), the first pattern in Figures 6 and 7. The experimental results for lattice parameters and lattice strains along the crystal axes $a$ and $c$ are shown in Figure $8 \mathrm{a}-\mathrm{d}$, for both phases. Linear fittings to the function $y=a+b p$ with fit parameters $a, b$ and pressure $p$ are represented by the continuous lines and numerical results inserted into the figures. To a first approximation, the overall strain response to pressure is $\partial \varepsilon / \partial p \approx-2.2 \times 10^{-3} \mathrm{GPa}^{-1}$ for both phases. However, details deviate from this average, resulting in anisotropy and inhomogeneity within and across the phases. This linear fitting leads to an approximation for the bulk modulus:

$$
K_{\text {lin }}=-V \frac{\partial p}{\partial V} \approx-(3 \partial \varepsilon / \partial p)^{-1} \approx 152 \mathrm{GPa}
$$

The crystallographic strain anisotropy is demonstrated by varying $c / a$ ratios, which are presented in Figure $8 \mathrm{e}, \mathrm{f}$ for both the $\gamma$ - and $\alpha_{2}$-phases. For pure $\alpha$-titanium, Zhang et al. [55] reported a constant, pressure-independent $2 c$ / $a$ ratio of 1.5868 , which agrees well with the generally-accepted value of 1.5871 (from JCPDS Card 44-1294) [56]. Controversially, a large pressure dependence has been reported by Errandonea et al. [48], which Zhang et al. refute and interpret as a response to deviatoric stresses, occurring in their diamond-anvil cell. In alloys, especially titanium aluminides, lattice parameters and $c / a$ ratios of both $\gamma$ - and $\alpha_{2}$-phases depend strongly on the composition of each phase, which varies as a function of temperature and segregation in multi-phase systems $[31,57,58]$. Increasing $2 c / a$ ratios of $\{1.60333,1.60432,1.60476\}$ with increasing $\mathrm{Al}$ content in single-phase $\alpha_{2} \mathrm{Ti}-\{24,28.4,33.3\} \mathrm{Al}$ have been measured by Dubrovinskaia et al. [59]. In the present study, we observed a slight variation of the $c$ / $a$ ratios with increasing pressure, in both phases, as shown in Figure $8 \mathrm{e}, \mathrm{f}$. The $c / a$ ratio in the $\gamma$-TiAl-phase decreases monotonically at an increasing rate with increasing pressure, towards a $c / a$ ratio approaching unity, the value for a cubic $f c c$ lattice. Such an $f c c$-Ti structure has been predicted by 
ab initio simulations [60,61], but it is energetically unstable and has not been experimentally observed. As a theoretically-postulated phase, it can be asymptotically used to interpret experimental data, such as for interpolating lattice parameters by Vegard's law [57].
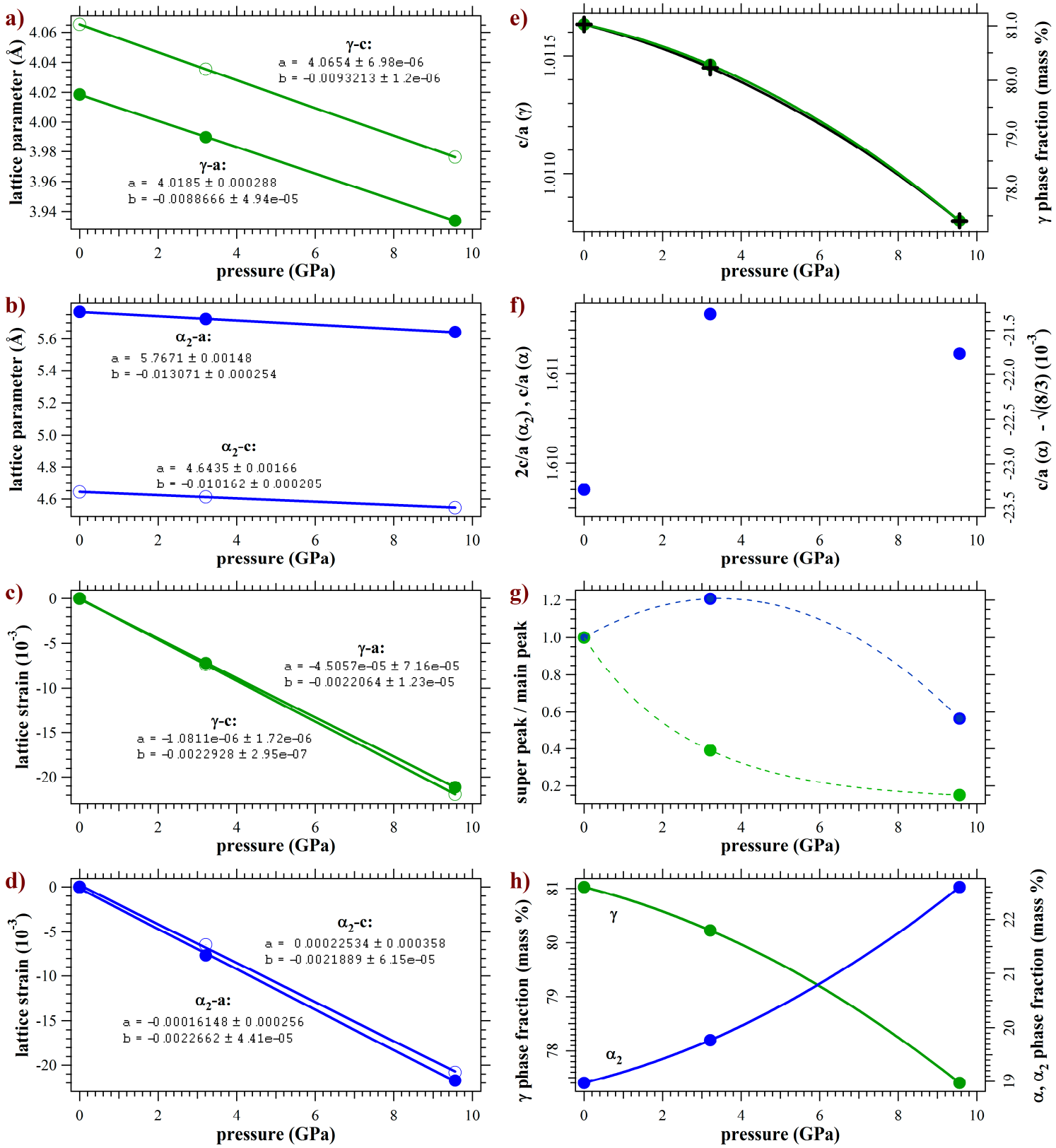

Figure 8. Evolution of structural parameters, phase fraction and diffraction intensity under pressure. Lattice parameters $(\mathbf{a}, \mathbf{b})$ and lattice strain $(\mathbf{c}, \mathbf{d})$ with linear fits $y=a+b p$; axis ratios $(\mathbf{e}, \mathbf{f})$; super-structure peak intensities, plotting ratios of super/main peak at pressure, normalized to the super/main peak at ambient pressure (g); and phase-fractions (h, superimposed to e).

In the case of $\gamma$-TiAl with a $\mathrm{L} 1_{0}$ structure, fully-disordered $\gamma_{\mathrm{d}}$-TiAl would be $f c c$, as the break of symmetry is expressed by the order. However, it is lacking even in a massively-transformed $\gamma$-phase [36]. It has been reported that $\gamma$ always tends to order, and when disordered, it transforms to the $\alpha-/ \alpha_{2}$-phase [31]. Moreover, for alloys with no added nucleants, in situ temperature studies on cooling from the disordered $\alpha$-phase consistently revealed significant undercooling below the $\alpha$-transus, where the $\gamma$-phase should re-appear. Watson et al. [40] correlated the delayed re-appearance 
of the latter with the ordering of $\alpha \rightarrow \alpha_{2}$, where lattice planes first partially order before the stacking sequence changes. Asta et al. [60] argue that for equi-atomic compositions, the $h c p$-based random alloy is slightly more stable than the $f c c$-based random alloy, and therefore, the stability of the $\gamma$-phase can be attributed to a stronger tendency to ordering of the $f c c$ lattice. In particular, the ordering energy is larger for the $\gamma$ structure than it is for the $\alpha_{2}$ structure.

In the present case, a continuous transformation from $\gamma$ to $\alpha / \alpha_{2}$ takes place with pressure, as presented in Figure 8h, which interestingly scales directly with the $c / a$ ratio of $\gamma$-TiAl, leading to the following scenario: with increasing pressure, atoms in the $\gamma$-phase are pressed towards the optimal close-packed $f c c$ structure, reducing its $c / a$ ratio. Inherent in this behavior is the introduction of disorder between the Ti and Al layers, facilitated by short range diffusion within the size of a unit cell. As disorder increases, the displacive character of the phase transformation $\gamma \rightarrow \alpha / \alpha_{2}$ becomes viable, in agreement with the arguments above and those advanced in the literature. Long-range diffusion and segregation do not occur at room temperature, while the pressure-driven disorder occurs throughout the bulk of the $\gamma$ grains, leading to the conclusion that ultrafine lamellae form, with thicknesses at the nanometer scale, in a manner very similar to low-temperature annealing of $\alpha$-quenched material [62-64]. The difference is that they may form on all four $\gamma\{111\}$ habit planes and lead to a Widmanstätten-like or basket-weave arrangement, rather than a lamellar microstructure. Such formation and disorder on a nanometer scale is supported by the micrographs of pressure loaded and unloaded $\gamma$-TiAl-based material published by Srinivasarao et al. [65]. Phase stresses in these ultrafine structured grains build up a large amount of potential energy, preventing further transformation at a given pressure and retaining the given $c / a$ ratio. The remaining disorder at the large density of interfaces leads to the observed decrease of superstructure reflections.

The anisotropic response of the $\alpha-/ \alpha_{2}$-phase is qualitatively different. Its $2 c / a$ ratio first increases when atoms are driven to a more ideally close-packed structure similar to the $\gamma$-phase, but then decreases slightly at higher pressure. In contrast to the $\gamma$-phase, the $\alpha-/ \alpha_{2}$-phases are a sink for disorder, both stoichiometrically and crystallographically. According to the phase diagram [66], the $\alpha_{2}-\mathrm{Ti}_{3} \mathrm{Al}$-phase is stable over a wide range of concentrations, between roughly Ti-20Al and Ti-35Al, even at room temperature. This indicates that up to $33 \%$ of either site can be accommodated by the wrong kind of atom, while the $\gamma$-TiAl formation begins at Ti- $47.5 \mathrm{Al}$ on the Ti-rich side, allowing only $5 \%$ of $\mathrm{Ti}$ on $\mathrm{Al}$ sites. In the present two-phase system, the compositions of the $\alpha_{2}$ - and $\gamma$-phases are expected to be sitting on the phase boundary lines, i.e., Ti-35Al and Ti-47.5Al, respectively. Furthermore, $\alpha_{2}$ fully disorders at high temperature (by a eutectoid reaction at $T_{\text {eu }}(0)=1453 \mathrm{~K}$ for our alloy), while $\gamma$ never does.

By considering the experimentally-derived data, the events occurring during pressurization can be clarified: In the first step, while no or little $\gamma$-phase transforms into $\alpha / \alpha_{2}$, atoms of $\alpha_{2}$ are pressed into their isotropic positions, i.e., towards ideally close-packed $2 c / a$. A high density of the nano-Widmanstätten or basket-weave structure propagates upon further pressure loading throughout the bulk of the grains, to create a relatively isotropic stress state in each volume (as compared to a lamellar microstructure) and introduces disorder, as evidenced by the decrease of the superstructure reflections shown in Figure 8g. Concurrent with a smaller $2 c / a$ in $\alpha$-Ti and thermal disorder in $\alpha$-TiAl [31], the $2 c / a$ ratio tends to decrease again, an argument that is well supported by the experimental data.

In summary, crystallographic disorder is being introduced into the phases upon loading at room temperature, where no long-range diffusion and annealing can occur. As the $\gamma$-phase disorders, it transforms into the $\alpha-/ \alpha_{2}$-phase, until transformation stresses built up to the extent that further transformation is impeded.

\subsubsection{Volumetric Response and Equation of State}

From a thermodynamic point of view, response to high pressure is given by the equation of state, relating the volume or density of the matter to pressure $p$, temperature $T$ and potentially other 
variables. A well-known equation of state is the ideal gas law. In the case of solids, the interaction potentials of atoms have to be taken into account [67]. Put simply, at constant temperature, atoms sit in the equilibrium position of superimposed attractive and repulsive parts of the potential, defining the bond distance. As hydrostatic pressure is increased, the applied load acts against the repulsive potential, shortening the bond distances and decreasing the volume occupied per atom. An important parameter related to the equation of state is the bulk modulus:

$$
K=-V \frac{\partial p}{\partial V}
$$

which is evaluated at a given temperature. It relates to the compressibility, mechanical properties, sound velocity, etc. For isotropic, linear strain, this corresponds to Equation (2) and for orthorhombic systems:

$$
\frac{\partial V}{V}=\sum_{i=a, b, c} \varepsilon_{i}
$$

For solids, there exist a multitude of atomic potential models, corresponding to a multitude of equations of state [68], but all of them should lead to the same bulk modulus $K_{0}=K(p=0)$, when properly evaluated at $p \rightarrow 0$. Physically, $K(p)$ is not constant, as a solid is more difficult to compress the further it is compressed. The detail of the potential reflects in the shape of the compression curve $V(p)$ as it deviates from linearity. As the non-linearity is small, it suffices to consider:

$$
K^{\prime}=\frac{\partial K}{\partial p}
$$

Sometimes, the details lie in the second derivative $K^{\prime \prime}$, for a second and third order fit, respectively.

The current case, with only three measured data points, allows the description of any second order curve in order of $K^{\prime}$, while fitting $K^{\prime \prime}$ would be an under-determined set of equations. Note, however, the change of derivative variable between Equations (3) and (5) and the functional behavior of a given equation of state, so that $K^{\prime \prime}$ may be implicitly determined in that equation. Therefore, the shape of the $V(p)$ curve depends on the equation used.

The most commonly-used equation is the Birch-Murnaghan equation of state [69,70], up to $200 \mathrm{GPa}$ [71], although at ultra-high pressure [61], the Vinet equation [72] is probably more accurate. In the present instance, we have fitted both equations and found that there is no significant difference; hence, our subsequent interpretation is not affected, and we present the Birch-Murnaghan approach.

The Birch-Murnaghan equation of state derives from the Helmholtz free energy and is typically Taylor expanded to the $n$-th order. The third order expansion is widely employed for the current type of high-pressure studies $[48,73,74]$ and provides three fitting parameters, $V, K_{0}, K_{0}{ }^{\prime}$ :

$$
p=\frac{3}{2} K_{0}\left\{\left(\frac{V}{V_{0}}\right)^{-\frac{7}{3}}-\left(\frac{V}{V_{0}}\right)^{-\frac{5}{3}}\right\}\left\{1+\frac{3}{4}\left(K_{0}^{\prime}-4\right)\left(\left(\frac{V}{V_{0}}\right)^{-\frac{2}{3}}-1\right)\right\}
$$

Volume occupations per atom have been calculated from the experimental unit cell and are displayed in Figure 9 and listed in Table 1, together with comparable results from the literature. The markers represent the experimental data points for the two phases, as well as for the total volume weighted by the phase fraction, while the continuous lines are fits to Equation (6). For comparison, the $V(p)$ behaviors of pure $\alpha$-Ti and $\omega$-Ti are shown, as taken from Errandonea et al. [48], as well as for $\alpha_{2}$ Ti-33.3Al from the study of Dubrovinskaia et al. [59]. The authors of the cited data also employed the Birch-Murnaghan equation, so that Equation (6) has been applied to the published parameters to compute the literature traces, transferred to volume per atom units.

Phases with a higher Al concentration consistently display a smaller volume per atom, due to the different atomic radii. To a first-order approximation, the compression curve of our $\alpha / \alpha_{2}$ data 
coincides very well with Dubrovinskaia's, which demonstrates that the measurements are accurate. In contrast to all of the examples given in the literature, i.e., $\alpha$-Ti, $\omega$-Ti and $\alpha_{2}-\mathrm{Ti}-33$.3Al, our curves start with a gentler slope of $V(p)$ and evolve more linearly, expressed by large $K_{0}$ and small $K_{0}{ }^{\prime}$ values. The observed bulk moduli, lying around $146 \mathrm{GPa}$, are significantly larger than reported elsewhere for related systems. Pure metals have smaller bulk moduli than intermetallic compounds, which have stronger bonds. This is underlined by Asta's first-principles computation on $f c c$ - and $h c p$-based Ti-Al compounds, showing that theoretically, $\gamma$-TiAl has one of the highest bulk moduli [60] (see Table 1), which still do not reach our experimental values. On the other hand, the presently-observed change of modulus $K_{0}^{\prime}$ with pressure is an order of magnitude smaller than otherwise earlier reported values.

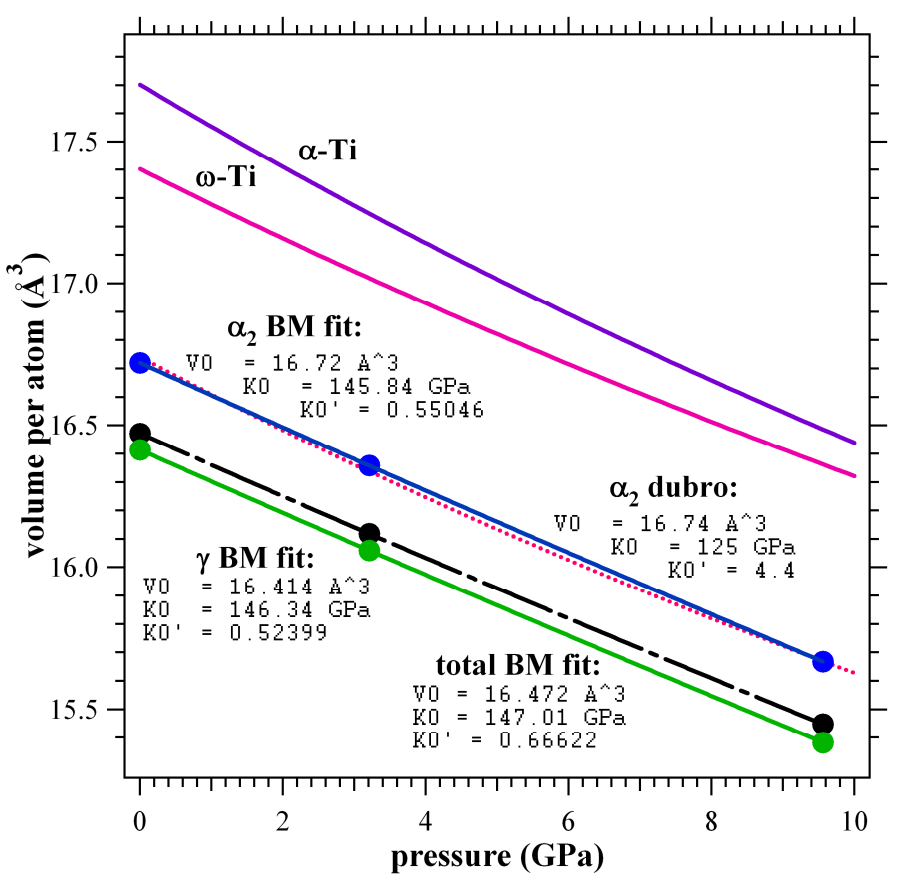

Figure 9. Atomic volumetric compression behavior of the investigated composition Ti-45Al-7.5Nb-0.25C with Birch-Murnaghan fits (experimental dots with continuous lines), as compared to $\alpha_{2}$-single-phase compression, and $\alpha$ - and $\omega$-titanium, reported by Dubrovinskaia [59] and Errandonea [48], respectively.

The salient difference between ours and earlier studies is that we are working in the $\left(\gamma+\alpha_{2}\right)$ two-phase field, where phases can transform continuously as a function of composition, temperature [66], disorder (see the discussion above) and pressure (see Figure $8 \mathrm{~h}$ ). A small change of these parameters will affect the relative phase fractions of $\gamma$ and $\alpha / \alpha_{2}$. All of the other cited pressure studies have been conducted in compositional single-phase fields. Dubrovinskaia et al. reported the absence of any pressure-induced phase transformation in $\alpha_{2} \mathrm{Ti}-33.3 \mathrm{Al}$, close to the border line with the $\left(\gamma+\alpha_{2}\right)$ two-phase-field. Therefore, we propose the following:

Upon loading, the atomic volume is reduced in each phase, and the phase transformation occurs, as discussed in Section 3.1.1, building up a nano-Widmanstätten (basket-weave) microstructure. The accumulating inter-phase stresses, highly interwoven and homogeneously distributed over the volumes of the initial grains, build up an additional potential acting against the applied pressure. As a consequence, the volume per atom, in each phase, is less compressed at any given pressure than it would be in its single-phase counterpart. As compression progresses, more and more material transforms, rather than pushing atoms against the repulsive potential, resulting in a seemingly increased bulk modulus. As such, a gradual phase transformation accommodates the response to hydrostatic pressure, rather than an increase of $K$, keeping $K^{\prime}$ small. It is interesting to note that the 
$\gamma$-phase, with a smaller atomic volume, transforms to the $\alpha-/ \alpha_{2}$-phase, with a larger volume per atom, driven by the strong ordering energy of $\gamma$ [60], as discussed in Section 3.1.1. Nevertheless, the total volume of the sample decreases with pressure, as given by the average atomic volume:

$$
V_{\mathrm{A}}^{\mathrm{avg}}=C_{\alpha} V_{A}^{\alpha}+C_{\gamma} V_{A}^{\gamma}
$$

$C_{\gamma}$ and $C_{\alpha}$ are the phase fractions of $\gamma$ and $\alpha / \alpha_{2}$, respectively, $\left(C_{\gamma}+C_{\alpha}=1\right)$, and are represented by the black markers and long-short-dashed line in Figure 9. The volume-increasing part $\gamma \rightarrow \alpha / \alpha_{2}$ of the transformation counteracts the volume compression in each phase, so that the total bulk modulus is even larger, and since the transformation rate itself is non-linear, it adds to the non-linearity of $V$, expressed as a slightly increased total $K^{\prime}$, compared to each individual phase; see Table 1 .

\subsection{Temperature Dependence at High Pressure}

The heating experiment was designed to determine if phase field shifts occur under pressure. In the current study, the sample was heated to the point of partial melting and data recorded during heating at various temperature holding points, while the maximum pressure of $9.6 \mathrm{GPa}$ was applied. Figure 7 shows the diffractograms as a function of room temperature loading and subsequent heating under constant load. The phase fractions of the alloy under investigation, Ti- $45 \mathrm{Al}-7.5 \mathrm{Nb}-0.25 \mathrm{C}$, obtained by Rietveld analysis, are depicted in Figure 10. Also included in the figure is the data of Yeoh et al. for a Ti-45Al-7.5Nb-0.5C alloy. Both alloys have been manufactured at the GKSS research center, Geesthacht, Germany, in a similar way and in consecutive batches [28] in order to study compositional effects only. The thermo-calorimetric and in situ diffraction studies undertaken by Chladil et al. [29] and Yeoh et al. [31] have been combined [30]. For Ti-45Al-7.5Nb- $x \mathrm{C}$ alloys, increasing carbon additions of $x \in\{0,0.25,0.5\} \%$ increase the eutectoid temperature $T_{\text {eu }}$ to $\{1432,1453,1473\} \mathrm{K}$, respectively, but otherwise, the transformation behavior is the same, specifically the $\gamma$-solvus or $\alpha$-transus remains stable at $T_{\alpha}=1565 \mathrm{~K}$. These expected transition temperatures $T_{\text {eu }}$ and $T_{\alpha}$ are marked in Figure 10 for the Ti-45Al-7.5Nb-0.25C used in this study. Although niobium is a $\beta$-phase stabilizer, $\beta$-containing phase fields were not detected in concentrations up to 7.5 at. \% [31], while higher concentrations above $8 \% \mathrm{Nb}$ rendered a detectable amount of this phase [30,75].

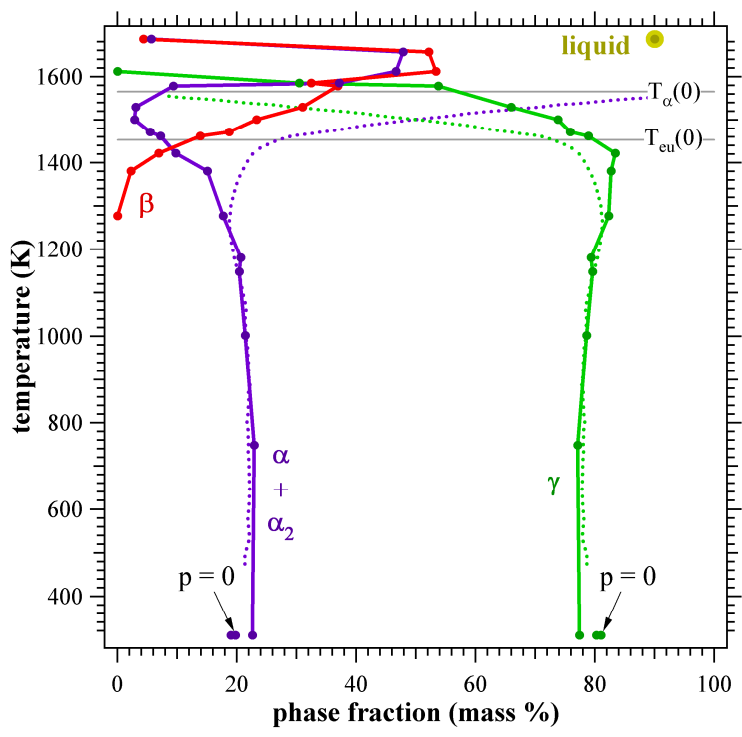

Figure 10. Phase evolution of Ti-45Al-7.5Nb-0.25C under high pressure at 9.6 GPa (continuous lines) in comparison to ambient pressure ( $p=0$ and dotted lines for Ti-45Al-7.5Nb-0.5C from Yeoh et al. [31]). The ambient pressure transition temperatures, reported by Chladil et al. [29], are marked for the investigated alloy. 
The salient difference between the high and the ambient pressure experiments lies in the appearance of a large fraction of $\beta$-phase above $\sim 1350 \mathrm{~K}$ in the high-pressure experiments, while no trace of this phase was experimentally observed in Yeoh's study [31]. Below $1350 \mathrm{~K}$, only $\alpha-/ \alpha_{2}$ - and $\gamma$-phases are present.

At ambient pressure, the $\gamma$ mass fraction is $81 \%$; it decreases gradually to $78.0 \%$ at $600 \mathrm{~K}$ before increasing above $1000 \mathrm{~K}$ to recover the maximum of $81 \%$ at $1250 \mathrm{~K}$. From this temperature, it decreases gradually up to the eutectoid temperature, $T_{\text {eu }}$, then diminishes at a high rate, up to $T_{\alpha}$, where it becomes fully $\alpha$-phase [31]. The cause of the minimization of the $\gamma$-phase between $600 \mathrm{~K}$ and $1000 \mathrm{~K}$ is attributed to local stacking rearrangements, where disorder, transitional structures $[62,63]$ or even intermediate phase transitions [76,77] may occur, depending on the composition and prior heat treatment. The induced disorder favors the $\gamma \rightarrow \alpha / \alpha_{2}$ transition, due to the high ordering potential in the $\gamma$-phase [60]. Order is expected to be highest at temperatures between 1200 and $1300 \mathrm{~K}$, resulting in the maximum amount of $\gamma$-phase [31].

Under a pressure of $9.6 \mathrm{GPa}$, the $\gamma$-fraction was reduced to $77.4 \%$ at room temperature; see Section 3.1.1. During heating, it reduces further to $77.1 \%$ at $750 \mathrm{~K}$, lying underneath the values of the ambient pressure heating, and then recovers while the difference vanishes at $810 \mathrm{~K}$. As lattice disorder and planar distortions were already induced at room temperature upon pressurizing, the $\gamma$-phase had transformed to $\alpha / \alpha_{2}$, which then reverts between $750 \mathrm{~K}$ and $810 \mathrm{~K}$, a temperature region known to show kinetics and planar re-arrangements [62,63]. Subsequently, mass fraction curves at both ambient and high-pressure overlap. While at ambient pressure, the $\gamma$-fraction begins to diminish at $1250 \mathrm{~K}$, it increases to a maximum of $83.4 \%$ at $1420 \mathrm{~K}$. Subsequently, with increasing temperature, $\gamma$ monotonically decreases until it vanishes at $T_{\gamma, \text { solv }}=1590 \mathrm{~K}$.

Table 1. Compilation of experimental lattice parameters $a_{0}$ and $c_{0}$ under ambient conditions, as well as the derived quantities; their axis ratios and volume per atom $V_{\mathrm{A}}$, compression parameters $K_{0}, K_{0}{ }^{\prime}$ (first 3 rows) and data from the literature. The $\alpha$-phase lattice is given in $\alpha_{2}$ cell notation, and therefore, $2 c / a$ is noted. The first $V_{\mathrm{A}}$ column is computed from $a_{0}$ and $c_{0}$, while the second results from the fit of pressure data to Equation (6). The original data of Yeoh's publication [31] has been re-visited to extract the listed values at $300 \mathrm{~K}$. Literature values are reported from their experimental findings, in addition to Ghosh's first-principles study [61]. Further listed references are Dubrovinskaia [59], Errandonea [48],

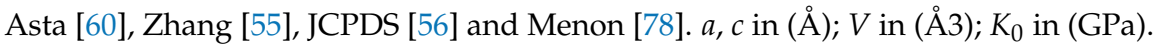

\begin{tabular}{|c|c|c|c|c|c|c|c|c|}
\hline Phase & $a_{0}$ & $c_{0}$ & $\begin{array}{l}\text { Axis } \\
\text { Ratio }\end{array}$ & $V_{\mathrm{A}}$ & $V_{\mathrm{A}}$ & $K_{0}$ & $K_{0}^{\prime}$ & Reference \\
\hline$\gamma$ & 4.01867 & 4.06542 & 1.0116332 & 16.4138371 & 16.414 & 146.34 & 0.52399 & this work \\
\hline$\alpha / \alpha_{2}$ & 5.76803 & 4.64241 & 1.60970383 & 16.7201111 & 16.72 & 145.84 & 0.55046 & this work \\
\hline total & & & & 16.4720291 & 16.472 & 147.01 & 0.66622 & this work \\
\hline$\alpha_{2}-\mathrm{Ti}-33.3 \mathrm{Al}$ & 5.7763 & 4.6348 & 1.6047643 & 16.7406041 & 16.74 & 125 & 4.4 & Dubrovinskaia \\
\hline$\alpha_{2}-\mathrm{Ti}-28.4 \mathrm{Al}$ & 5.7829 & 4.6388 & 1.60431617 & 16.7933623 & 16.79375 & 131 & 3.6 & Dubrovinskaia \\
\hline$\alpha_{2}-\mathrm{Ti}-24.0 \mathrm{Al}$ & 5.8083 & 4.6563 & 1.60332627 & 17.0051191 & 17.005 & 133 & 2.6 & Dubrovinskaia \\
\hline$\alpha-\mathrm{Ti}$ & & & 1.583 & & 17.7013462 & 117 & 3.9 & Errandonea \\
\hline$\omega-\mathrm{Ti}$ & & & 0.609 & & 17.4024491 & 138 & 3.8 & Errandonea \\
\hline$\gamma$ & & & 1.012 & & & 128 & & Asta \\
\hline$\alpha_{2}$ & & & 1.698 & & & 126 & & Asta \\
\hline$\gamma$ & 3.9814 & 4.0803 & 1.02484051 & 16.1697657 & 16.181 & 112.1 & 3.91 & Ghosh \\
\hline$\alpha_{2}$ & 5.7372 & 4.6825 & 1.63232936 & 16.6847003 & 16.584 & 111.9 & 3.83 & Ghosh \\
\hline$\alpha-\mathrm{Ti}$ & & & 1.5868 & & & 114 & 4 & Zhang \\
\hline$\alpha-\mathrm{Ti}$ & 5.901 & 4.6826 & 1.58705304 & 17.651391 & & & & JCPDS \\
\hline$\gamma$-Ti-50Al & 3.9973 & 4.0809 & 1.02091412 & 16.3015706 & & & & Menon \\
\hline$\gamma$-Ti-45Al-7.5Nb-0.5C & 4.02421 & 4.07335 & 1.01221109 & 16.4912285 & & & & Yeoh \\
\hline$\alpha_{2}-\mathrm{Ti}-45 \mathrm{Al}-7.5 \mathrm{Nb}-0.5 \mathrm{C}$ & 5.77568 & 4.65646 & 1.61243698 & 16.8152283 & & & & Yeoh \\
\hline
\end{tabular}

At a pressure of $9.6 \mathrm{GPa}$, a coexisting, third phase, $\beta$, with $a=3.20 \AA$, appears at $1350 \mathrm{~K}$, in stark contrast to heating at ambient pressure. It is apparent that in large measure, $\alpha_{2}$ transforms to $\beta\left(\alpha_{2} \rightarrow \beta\right)$, evidenced by the increasing fraction of $\gamma$, below $1420 \mathrm{~K}$. As the fraction of $\gamma$ decreases on further heating, the fraction of $\beta$ increases due to the intermediate formation of $\alpha / \alpha_{2}$. A minimum fraction 
of $\alpha / \alpha_{2}, 2.9 \%$ at $1510 \mathrm{~K}$, suggests that a disordering transition $\alpha_{2} \rightarrow \alpha$ occurs at $T_{\text {eu }}$, above which the $\alpha$-phase fraction increases again, due to the transformation of $\gamma$. The suggested transformation sequence $\gamma \rightarrow \alpha \rightarrow \alpha+\beta$ is evidenced as supported by the rates of transformation: Initially, $\alpha$ transforms to $\beta$, then as $\gamma$ transforms more rapidly, the $\alpha$-phase fraction catches up, while the $\beta$ formation decreases. When $\gamma$ disappears abruptly at $T_{\gamma, \text { solv }}=1590 \mathrm{~K}$, the $\alpha$-phase fraction increases sharply, and the $\beta$-phase decreases temporarily from $36.9 \%$ to $32.4 \%$, which immediately recovers to $53 \% \beta+47 \% \alpha$ in the two-phase-field. Above $1660 \mathrm{~K}$, the alloy starts to melt, while the $\sim 50 / 50$ solid-phase ratio is maintained.

The appearance of the $\beta$-phase at high pressure has important implications for the deformation behavior of this material, in particular during high-pressure near-conventional forging and shaping. Liss et al. [7] have demonstrated by in situ experiments that the plastic deformation behavior of a $\beta$-stabilized Ti-43.5Al-4Nb-1Mo-0.1B alloy in the $(\alpha+\beta)$ two-phase field at $1573 \mathrm{~K}$ occurs by fast dynamic recovery of the $\beta$-phase, while the co-existing $\alpha$-grains deform primarily by slip, with slow dynamic recovery and results in even lesser dynamic recrystallization. In this scenario, the dynamically-recovering $\beta$-phase allows for deformation to accommodate the harder $\alpha$-phase grains embedded therein. Deformation of the same material at $1493 \mathrm{~K}$ in the $(\alpha+\beta+\gamma)$-phase field leads, qualitatively, to the conclusion that $\beta$ is the actively deforming phase, while $\alpha$ and $\gamma$ grains display greater stiffness [79]. This high kinetic activity of the $\beta$-phase is due to phonon softening, relating to extremely high self-diffusion, in the relatively open $b c c$ lattice $[47,80]$. This results in rapid dynamic recrystallization, recovery and grain growth, which in essence, eradicates almost any deformation texture of this phase [7]. Microscopic and electron-backscatter-diffraction studies have subsequently confirmed this behavior [79,81].

These compositionally $\beta$-stabilized alloys are being developed for near-conventional, near-net-shape forging production since conventional $(\alpha+\gamma)$ TiAl alloys are prone to brittleness and highly anisotropic plastic behavior, which is related to the strongly ordered $\gamma$ - and the hexagonal, $h c p \alpha$-phases. Clemens and Mayer [10] proposed the development of an alloy that contains a relatively large fraction of $\beta$-phase at processing temperatures, while the fraction of $\beta$-phase is minimized at the expected operation temperatures in, for example, a Ti-43.5Al-4Nb-1Mo-0.1B alloy. However, the residual $\beta$-fraction would reduce the alloy's resistance to creep, and it is therefore essential to minimize the amount of $\beta$ below $1100 \mathrm{~K}$.

Although the $\beta$-phase is usually prone to rapid grain growth, Liss [7,39] and Kabra [82] found, by conducting in situ diffraction studies, that grain growth is inhibited in a multi-phase alloy, even in a $\beta$-phase containing titanium or zirconium alloy. This is in large part due to segregation, as different phases have distinct compositions and require long-range diffusion for grain growth to occur. Therefore, in two- or multiple-phase materials, the grain size is relatively stable, even at elevated forging temperatures.

Under the conditions pertaining to the present study, all of these requirements are optimally fulfilled, as no $\beta$-phase is present in the $\left(\alpha / \alpha_{2}+\gamma\right)$ two-phase field, up to $\sim 1350 \mathrm{~K}$, well above the expected operating temperatures of this material. Conversely, the ductile $\beta$-phase is abundant under high pressure in both three- and two-phase regions, potentially giving rise to a large thermo-mechanical processing window. Even a small $\beta$-phase fraction, between $5 \%$ and $15 \%$, leads to good plasticity in both $(\alpha+\beta+\gamma)$ - and $(\alpha+\beta)$-phase fields [79]. The present study highlights the potential to develop new processing routes by optimizing the fraction of the ductile $\beta$-phase by a judicious selection of a temperatures and pressure, in all three $\left(\alpha_{2}+\beta+\gamma\right)-,(\alpha+\beta+\gamma)$ - and $(\alpha+\beta)$-phase fields. For example, grains of the ordered structures $\alpha_{2}$ and $\gamma$ may be largely conserved while being rearranged through plastic deformation of the $\beta$-phase. Alternatively, a minimum $\alpha$ fraction can be chosen for larger and superplastic deformations, minimizing anisotropy, i.e., texture, or even deformation without the $\gamma$-phase for extreme and rapid forging. 


\section{Conclusions}

The response of a $\gamma$-titanium aluminide-based, two-phase alloy of composition Ti-45Al-7.5Nb-0.25C to high pressure and temperature has been investigated, leading to unprecedented results, regarding the evolution of lattice parameters, atomic volume and phase transformations.

The pressure-induced appearance of the $b c c \beta$-phase above $1350 \mathrm{~K}$ and at $9.6 \mathrm{GPa}$ is the salient result for potential manufacturing applications, such as high-pressure forging, while at conventional pressures, this phase is not abundant under operational conditions, such as in the turbines of a jet-engine. It renders the possibility of good forgeability at achievable processing temperatures coupled with phase stability and creep resistance at the expected operating conditions of the alloy.

The large amount of $\beta$-phase found at high pressure and temperature, supported by the pressure-temperature phase diagram of pure titanium, suggests that this phase is stabilized at much lower concentrations of niobium, and this can ultimately lead to the development of niobium-free, binary titanium aluminides.

Under room temperature pressure loading, $\gamma$-phase gradually transforms to $\alpha / \alpha_{2}$, driven by local disordering of $\gamma$, while atoms are pressed towards their close-packed $f_{c c}$ positions. Since the $\gamma$ $\rightarrow \alpha / \alpha_{2}$ transition is largely displacive, planar faults build up on all of the equivalent $\gamma\{111\}$ planes, producing ultrafine lathes in a nano-Widmanstätten or basket-weave arrangement, introducing more disorder into both co-existing phases.

No phase transformations have been reported in the literature on pressurizing single-phase $\gamma$ or $\alpha_{2}$ titanium aluminides. The fact that we are working in a two-phase field allows gradual transformation between the two during loading.

Due to the ordering energy in the $\gamma$-phase being the highest, the system is forced to transform, $\gamma \rightarrow \alpha / \alpha_{2}$, even though the newly-formed product phase occupies a larger volume per atom than the mother phase. However, the total volume of the specimen, when weighted by the phase fraction and the individual bulk moduli, is still reduced with increasing pressure.

A Murnaghan-Birch equation of state has been fitted to the two individual, co-existing phases $\gamma$ and $\alpha / \alpha_{2}$, as well as to the total weighted volume reduction. With values around $146 \mathrm{GPa}$, the bulk moduli $K$, fitted to the individual phases, are significantly higher than the values reported in the literature (see Table 1 ). Conversely, its pressure derivative, $K^{\prime}$, is an order of magnitude smaller than the values reported in the literature, since the volume response to pressure is accommodated by the $\gamma \rightarrow \alpha / \alpha_{2}$ phase transformation, underlined by the even higher total bulk modulus, fitted to the weighted atomic volume.

Accordingly, a Murnaghan-Birch type equation, based on solely attractive and repulsive atomic potentials, is insufficient to describe the present case: a term describing the phase transformations together with the above-mentioned ordering energies needs to be introduced.

The room-temperature transformation builds up a large amount of mechanically-stored energy, which eventually balances the disorder energy in the $\gamma$-phase. Upon heating under pressure, the system largely recovers between $750 \mathrm{~K}$ and $810 \mathrm{~K}$, following the ambient-pressure phase fractions up to $1250 \mathrm{~K}$.

Under high pressure, the solid-solid transition temperatures are shifted to higher values. The fraction of $\gamma$-phase increases to a maximum at $1420 \mathrm{~K}$, while at ambient pressure, the maximum is reached at $1250 \mathrm{~K}$. The sharp $\gamma$-phase dissolution temperature $T_{\gamma \text {,solv }}$ is increased, as well as the eutectoid temperature $T_{\text {eu }}$ for $\alpha_{2} \rightarrow \alpha$ is expected at the minimum of the $\alpha$ fraction (see Table 2).

Table 2. Transition and other distinct temperatures. Ambient pressure values after [29].

\begin{tabular}{cccccccc}
\hline \multicolumn{4}{c}{ Ambient Pressure [29] } & \multicolumn{5}{c}{ High Pressure: 9.6 GPa } \\
\hline $\operatorname{Max} \gamma$ & Eutectoid & $\boldsymbol{\gamma}$-Solvus & $\operatorname{Max} \boldsymbol{\gamma}$ & $\operatorname{Min} \boldsymbol{\alpha}$ & $\boldsymbol{\gamma}$-Solvus & $\boldsymbol{\beta}$ Start & Solidus \\
\hline$T_{\gamma, \max }(0)$ & $T_{\text {eu }}(0)$ & $T_{\boldsymbol{\alpha}} T_{\gamma, \text { solv }}(0)$ & $T_{\gamma, \max }$ & $T_{\boldsymbol{\alpha} \text {,min }}\left(T_{\text {eu }}\right)$ & $T_{\gamma, \text { solv }}$ & $T_{\boldsymbol{\beta}, \text { start }}$ & $T_{\mathrm{m}}$ \\
$1250 \mathrm{~K}$ & $1453 \mathrm{~K}$ & $1565 \mathrm{~K}$ & $1420 \mathrm{~K}$ & $1510 \mathrm{~K}$ & $1590 \mathrm{~K}$ & $1350 \mathrm{~K}$ & $1660 \mathrm{~K}$ \\
\hline
\end{tabular}


Starting at $\sim 1350 \mathrm{~K}$, approximately half of the $\alpha-/ \alpha_{2}$-phase transforms to the high-pressure $\beta$-phase, which plays an important role in the transformation kinetics. At $T_{\text {eu }}$, the $\alpha-/ \alpha_{2}$-phase is at a minimum, and above $T_{\gamma}$, it increases again, before the solid starts to melt above $>1660 \mathrm{~K}$.

The ductile $\beta$-phase is present in three regions, namely $\left(\alpha_{2}+\beta+\gamma\right),(\alpha+\beta+\gamma)$ and $(\alpha+\beta)$, while the highly anisotropic phases $\alpha / \alpha_{2}$ show a minimum of $2.9 \%$, which potentially allows for the adjustment of processing parameters to property requirements and optimization.

The present study is the first of its kind in a two-phase titanium aluminide intermetallic, a composition of considerable technological importance for high-temperature applications and which has been the focus of fundamental research for over 25 years. Recently, titanium aluminides have been successfully implemented as high-temperature components in airplane jet engines. Regarding the development of giga-newton super presses, near-conventional forging of such material under high pressure becomes feasible. While the first fundamental results under high pressure and high temperature have been presented here, there remains a number of questions, such as more detailed studies of the pressurization process and an equation of state incorporating pressure, temperature, composition and atomic order. The latter should lead to neutron scattering experiments, feasible at the PLANET beamline of the J-PARC facility [83], not only to investigate ordered $\alpha_{2}$, but also ordered $\beta_{\mathrm{o}}$. Based on the pressure-temperature phase diagram of pure titanium, we predict that the high-temperature, high-pressure-induced $\beta$-phase is stabilized over a wide range of TiAl-based alloys, including binary $\left(\alpha_{2}+\gamma\right)$ titanium aluminides, which opens an extraordinary variety of alloy designs, processing and applications.

Note that essential to this study is the employment of a large volume pressure apparatus, which allows the evolution of a realistic microstructure in a realistic sample volume, rather than a micro- to nanometer-sized sample in a diamond anvil cell. Modern multi-anvil apparatuses, such as PLANET, also allow the addition of uni-axial stress components [84], enabling the study of in situ plastic deformation under high pressure. Similar complex high-pressure machines evolve at synchrotron sources [42,43], and the usage of two-dimensional detectors [85] has also been realized, which then will allow the investigation of various deformation mechanisms and kinetics, by evaluation, such as in a materials oscilloscope [38,39].

Acknowledgments: The authors are grateful to Dr. habil. Arno Bartels, Technische Universität Hamburg-Harburg, Germany, for providing the sample material. M.R. greatly acknowledges travel funding from the School of Mechanical, Mechatronics \& Materials Engineering, University of Wollongong, Australia. The synchrotron radiation experiments were performed at the beamline BL04B1 of SPring- 8 with the approval of the Japan Synchrotron Radiation Research Institute (JASRI) (Proposal No. 2013B1157).

Author Contributions: The research was conceived of by K.-D.L., K.A., R.J.D. and H.S., who applied for the beam time. K.-I.F. and Y.H. designed the experimental setup and the pressure cell, which was manufactured by A.S., K.-I.F. and T.S., H.S. manufactured the samples. H.S., K.A., M.R. and K.-I.F. assembled the sample cells, while K.-I.F., M.R., Y.H. and K.-D.L. prepared the instrument. The diffraction experiments were run by all, but R.J.D., K.-D.L. undertook all post-experimental data analysis and wrote the first version of the manuscript. All authors checked and improved the manuscript. Figure 11 shows the investigators and support staff (Y.H. and R.J.D. are missing).

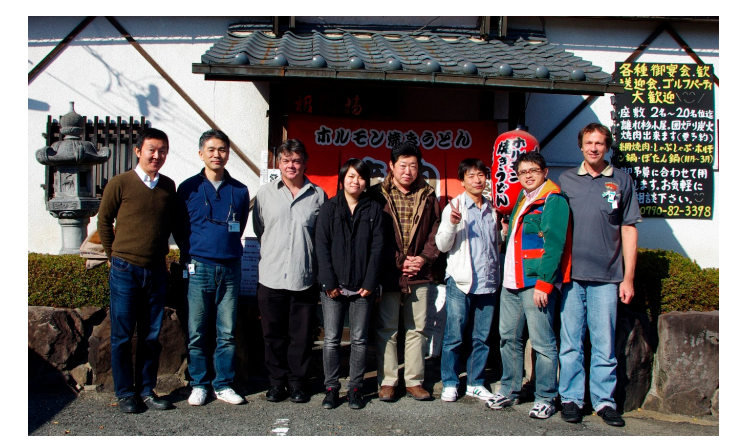

Figure 11. The experimentalists: support staff, Shuoyuan Zhang, and some of the authors, Koichi Akita, Mark Reid, Ayumi Shiro, Ken-ichi Funakoshi, Takahisa Shobu, Hiroshi Suzuki and Klaus-Dieter Liss. 
Conflicts of Interest: The authors declare no conflict of interest.

\section{Abbreviations}

$\begin{array}{ll}f c c & \text { face-centered cubic } \\ b c c & \text { body-centered cubic } \\ h c p & \text { hexagonal close-packed } \\ \text { YAG } & \text { yttrium aluminium garnet, } \mathrm{Y}_{3} \mathrm{Al}_{5} \mathrm{O}_{12} \\ \text { CCD } & \text { charged coupled device } \\ \text { SSD } & \text { solid-state detector } \\ \text { TNB } & \text { TiAl-Nb alloy }\end{array}$

\section{References}

1. Lipsitt, H.A. Titanium Aluminides-An Overview. MRS Proc. 1984, 39, 351-364. [CrossRef]

2. Kothari, K.; Radhakrishnan, R.; Wereley, N.M. Advances in gamma titanium aluminides and their manufacturing techniques. Prog. Aerosp. Sci. 2012, 55, 1-16. [CrossRef]

3. Gupta, R.K.; Ramkumar, P. Titanium Aluminides for Metallic Thermal Protection System of Reusable Space Transportation Vehicle: A Review. Front. Aerosp. Eng. 2015, 4, 14-19. [CrossRef]

4. Clemens, H.; Mayer, S. Intermetallic titanium aluminides in aerospace applications-Processing, microstructure and properties. Mater. High Temp. 2016. [CrossRef]

5. Yang, R. Advances and challenges of TiAl base alloys. Acta Metall. Sin. 2015, 51, 129-147.

6. Clemens, H.; Schloffer, M.; Schwaighofer, E.; Werner, R.; Gaitzenauer, A.; Rashkova, B.; Schmoelzer, T.; Pippan, R.; Mayer, S. Advanced $\beta$-Solidifying Titanium Aluminides-Development Status and Perspectives. In Symposium JJ-Intermetallic-Based Alloys-Science, Technology and Applications; Materials Research Society: Warrendale, PA, USA, 2013; Volume 1516, pp. 3-16.

7. Liss, K.-D.; Schmoelzer, T.; Yan, K.; Reid, M.; Peel, M.; Dippenaar, R.; Clemens, H. In situ study of dynamic recrystallization and hot deformation behavior of a multiphase titanium aluminide alloy. J. Appl. Phys. 2009, 106, 113526:1-113526:6. [CrossRef]

8. Appel, F.; Oehring, M.; Paul, J.D.H.; Klinkenberg, C.; Carneiro, T. Physical aspects of hot-working gamma-based titanium aluminides. Intermetallics 2004, 12, 791-802. [CrossRef]

9. Erdely, P.; Schmoelzer, T.; Schwaighofer, E.; Clemens, H.; Staron, P.; Stark, A.; Liss, K.-D.; Mayer, S. In Situ Characterization Techniques Based on Synchrotron Radiation and Neutrons Applied for the Development of an Engineering Intermetallic Titanium Aluminide Alloy. Metals 2016, 6. [CrossRef]

10. Clemens, H.; Mayer, S. Design, Processing, Microstructure, Properties, and Applications of Advanced Intermetallic TiAl Alloys. Adv. Eng. Mater. 2013, 15, 191-215. [CrossRef]

11. Zhilyaev, A.P.; Langdon, T.G. Using high-pressure torsion for metal processing: Fundamentals and applications. Prog. Mater. Sci. 2008, 53, 893-979. [CrossRef]

12. Yan, K.; Bhattacharyya, D.; Lian, Q.; Kabra, S.; Kawasaki, M.; Carr, D.G.; Callaghan, M.D.; Avdeev, M.; Li, H.; Wang, Y.; et al. Martensitic Phase Transformation and Deformation Behavior of Fe-Mn-C-Al Twinning-Induced Plasticity Steel during High-Pressure Torsion. Adv. Eng. Mater. 2014, 16, 927-932. [CrossRef]

13. Edalati, K.; Toh, S.; Iwaoka, H.; Watanabe, M.; Horita, Z.; Kashioka, D.; Kishida, K.; Inui, H. Ultrahigh strength and high plasticity in TiAl intermetallics with bimodal grain structure and nanotwins. Scr. Mater. 2012, 67, 814-817. [CrossRef]

14. Alhamidi, A.; Edalati, K.; Horita, Z. Production of nanograined intermetallics using high-pressure torsion. Mater. Res. 2013, 16, 672-678. [CrossRef]

15. Krämer, L.; Kormout, K.S.; Setman, D.; Champion, Y.; Pippan, R. Production of Bulk Metallic Glasses by Severe Plastic Deformation. Metals 2015, 5, 720-729. [CrossRef]

16. France-Métallurgie. Blog Archive China's 80,000-Ton Press Forge Almost Ready for Use (US). Available online: http:/ / www.france-metallurgie.com/index.php/2013/03/18/chinas-80000-ton-press-forge-almostready-for-use-us / (accessed on 10 June 2016).

17. Altan, T.; Semiatin, S.L. Feasibility of Using a Large Press (80,000-200,000 Ton) for Manufacturing Future Components on Army Systems; U.S. Army Tank-Automotive Command Research and Development Center: Warren, MI, USA, 1983. 
18. The Machines that Made the Jet Age /Boing Boing. Available online: http:/ /boingboing.net/2012/02/13/ machines.html (accessed on 10 June 2016).

19. Huber, D.; Werner, R.; Clemens, H.; Stockinger, M. Influence of process parameter variation during thermo-mechanical processing of an intermetallic $\beta$-stabilized $\gamma$-TiAl based alloy. Mater. Charact. 2015, 109, 116-121. [CrossRef]

20. Li, X.-S.; Wang, H.-Y.; Li, C.-Y.; Mi, G.-F.; Hu, Q.-K. Structural and Thermodynamic Properties of TiAl intermetallics under High Pressure. Commun. Theor. Phys. 2012, 57, 141-144. [CrossRef]

21. Young, D.A. Phase Diagrams of the Elements; University of California Lawrence Livermore Laboratory: Livermore, CA, USA, 1975.

22. Jayaraman, A.; Klement, W.; Kennedy, G.C. Solid-Solid Transitions in Titanium and Zirconium at High Pressures. Phys. Rev. 1963, 131, 644-649. [CrossRef]

23. Bystrzanowski, S.; Bartels, A.; Stark, A.; Gerling, R.; Schimansky, F.-P.; Clemens, H. Evolution of microstructure and texture in Ti-46Al-9Nb sheet material during tensile flow at elevated temperatures. Intermetallics 2010, 18, 1046-1055. [CrossRef]

24. Appel, F.; Brossmann, U.; Christoph, U.; Eggert, S.; Janschek, P.; Lorenz, U.; Müllauer, J.; Oehring, M.; Paul, J.D.H. Recent Progress in the Development of Gamma Titanium Aluminide Alloys. Adv. Eng. Mater. 2000, 2, 699-720. [CrossRef]

25. Appel, F.; Oehring, M.; Wagner, R. Novel design concepts for gamma-base titanium aluminide alloys. Intermetallics 2000, 8, 1283-1312. [CrossRef]

26. Appel, F. Recent Developments in the Design and Processing of Gamma-Based Titanium Aluminide Alloys. Mater. Sci. Forum 2003, 426-432, 91-98. [CrossRef]

27. Bystrzanowski, S. Creep Behavior and Microstructure Stability of the Ti-46Al-9Nb Sheet Material; Shaker Verlag $\mathrm{GmbH}$ : Aachen, Germany, 2005.

28. Gerling, R.; Clemens, H.; Schimansky, F.P. Powder Metallurgical Processing of Intermetallic Gamma Titanium Aluminides. Adv. Eng. Mater. 2004, 6, 23-38. [CrossRef]

29. Chladil, H.F.; Clemens, H.; Leitner, H.; Bartels, A.; Gerling, R.; Schimansky, F.-P.; Kremmer, S. Phase Transformations in High Niobium and Carbon Containing $\gamma$-TiAl Based Alloys. Intermetallics 2006, 14, 1194-1198. [CrossRef]

30. Chladil, H.F.; Clemens, H.; Zickler, G.A.; Takeyama, M.; Kozeschnik, E.; Bartels, A.; Buslaps, T.; Gerling, R.; Kremmer, S.; Yeoh, L.; et al. Experimental studies and thermodynamic simulation of phase transformations in high $\mathrm{Nb}$ containing gamma-TiAl based alloys. Int. J. Mater. Res. 2007, 98, 1131-1137. [CrossRef]

31. Yeoh, L.A.; Liss, K.-D.; Bartels, A.; Chladil, H.; Avdeev, M.; Clemens, H.; Gerling, R.; Buslaps, T. In situ high-energy X-ray diffraction study and quantitative phase analysis in the alpha plus gamma phase field of titanium aluminides. Scr. Mater. 2007, 57, 1145-1148. [CrossRef]

32. Pecker, S.; Eliezer, S.; Fisher, D.; Henis, Z.; Zinamon, Z. A multiphase equation of state of three solid phases, liquid, and gas for titanium. J. Appl. Phys. 2005, 98, 043516:1-043516:12. [CrossRef]

33. Greene, R.G.; Luo, H.; Ruoff, A.L. Al as a Simple Solid: High Pressure Study to $220 \mathrm{GPa}$ (2.2 Mbar). Phys. Rev. Lett. 1994, 73, 2075-2078. [CrossRef] [PubMed]

34. Quantum Beam Science-An Open Access Journal from MDPI; Rittman, M., Liss, K.-D., Eds.; MDPI: Basel, Switzerland, 2016.

35. Shull, R.D.; Cline, J.P. High Temperature X-ray Diffractometry of Ti-Al Alloys. In Materials Chemistry at High Temperatures; Hastie, J.W., Ed.; Humana Press: Totowa, NJ, USA, 1990; pp. 95-117.

36. Liss, K.-D.; Bartels, A.; Clemens, H.; Bystrzanowski, S.; Stark, A.; Buslaps, T.; Schimansky, F.-P.; Gerling, R.; Scheu, C.; Schreyer, A. Recrystallization and phase transitions in a gamma-TiAl-based alloy as observed by ex situ and in situ high-energy X-ray diffraction. Acta Mater. 2006, 54, 3721-3735. [CrossRef]

37. Liss, K.-D.; Bartels, A.; Schreyer, A.; Clemens, H. High-energy X-rays: A tool for advanced bulk investigations in materials science and physics. Textures Microstruct. 2003, 35, 219-252. [CrossRef]

38. Liss, K.-D. In situ diffraction studies related to thermo-mechanical processes. In Proceedings of the ICCE-23: Annual International Conference on Composites and Nano-Engineering, Chengdu, China, 12-18 July 2015.

39. Liss, K.-D.; Yan, K. Thermo-mechanical processing in a synchrotron beam. Mater. Sci. Eng. A 2010, 528, 11-27. [CrossRef] 
40. Watson, I.J.; Liss, K.-D.; Clemens, H.; Wallgram, W.; Schmoelzer, T.; Hansen, T.C.; Reid, M. In Situ Characterization of a $\mathrm{Nb}$ and Mo Containing gamma-TiAl Based Alloy Using Neutron Diffraction and High-Temperature Microscopy. Adv. Eng. Mater. 2009, 11, 932-937. [CrossRef]

41. Kabra, S.; Yan, K.; Mayer, S.; Schmoelzer, T.; Reid, M.; Dippenaar, R.; Clemens, H.; Liss, K.-D. Phase transition and ordering behavior of ternary Ti-Al-Mo alloys using in situ neutron diffraction. Int. J. Mater. Res. 2011, 102, 697-702. [CrossRef]

42. Chen, B.; Lin, J.-F.; Chen, J.; Zhang, H.; Zeng, Q. Synchrotron-based High Pressure Research in Materials Science. MRS Bull. 2016, 41, 473-478. [CrossRef]

43. Liss, K.-D.; Chen, K. Frontiers of synchrotron research in materials science. MRS Bull. 2016, 41, 435-441. [CrossRef]

44. Errandonea, D. Transition metals: Can metals be a liquid glass? Nat. Mater. 2009, 8, 170-171. [CrossRef] [PubMed]

45. Utsumi, W.; Funakoshi, K.; Urakawa, S.; Yamakata, M.; Tsuji, K.; Konishi, H.; Shimomura, O. SPring-8 Beamlines for High Pressure Science with Multi-Anvil Apparatus. Rev. High Press. Sci. Technol. 1998, 7, 1484-1486. [CrossRef]

46. Utsumi, W.; Funakoshi, K.; Katayama, Y.; Yamakata, M.; Okada, T.; Shimomura, O. High-pressure science with a multi-anvil apparatus at SPring-8. J. Phys. Condens. Matter 2002, 14. [CrossRef]

47. Hattori, T.; Saitoh, H.; Kaneko, H.; Okajima, Y.; Aoki, K.; Utsumi, W. Does Bulk Metallic Glass of Elemental Zr and Ti Exist? Phys. Rev. Lett. 2006, 96. [CrossRef] [PubMed]

48. Errandonea, D.; Meng, Y.; Somayazulu, M.; Häusermann, D. Pressure-induced transition in titanium metal: A systematic study of the effects of uniaxial stress. Phys. B Condens. Matter 2005, 355, 116-125. [CrossRef]

49. Tange, Y.; Higo, Y. BL04B1: In Situ Observation of High Pressure Phase Change of Simple Material; SPring-8, Asia Oceania Forum for Synchrotron Radiation Research: Kouto, Japan, 2007.

50. Katsura, T.; Funakoshi, K.; Kubo, A.; Nishiyama, N.; Tange, Y.; Sueda, Y.; Kubo, T.; Utsumi, W. A large-volume high-pressure and high-temperature apparatus for in situ X-ray observation, 'SPEED-Mk.II'. Phys. Earth Planet. Int. 2004, 143-144, 497-506. [CrossRef]

51. Speziale, S.; Zha, C.-S.; Duffy, T.S.; Hemley, R.J.; Mao, H. Quasi-hydrostatic compression of magnesium oxide to 52 GPa: Implications for the pressure-volume-temperature equation of state. J. Geophys. Res. Solid Earth 2001, 106, 515-528. [CrossRef]

52. Shim, S.-H.; Duffy, T.S.; Takemura, K. Equation of state of gold and its application to the phase boundaries near 660 km depth in Earth's mantle. Earth Planet. Sci. Lett. 2002, 203, 729-739. [CrossRef]

53. Seto, Y.; Nishio-Hamane, D.; Nagai, T.; N. Sata, N. Development of a software suite on X-ray diffraction experiments. Rev. High Pressure Sci. Technol. 2010, 20, 269-276. [CrossRef]

54. Lutterotti, L. Total pattern fitting for the combined size-strain-stress-texture determination in thin film diffraction. Nucl. Instrum. Methods Phys. Res. Sect. B 2010, 268, 334-340. [CrossRef]

55. Zhang, J.; Zhao, Y.; Hixson, R.S.; Gray, G.T.; Wang, L.; Utsumi, W.; Saito, H.; Hattori, T. Thermal equations of state for titanium obtained by high pressure/temperature diffraction studies. Phys. Rev. B 2008, 78, 054119:1-054119:7. [CrossRef]

56. Titanium-Card No 44-1294; Joint Committee on Powder Diffraction Standards (JCPDS)—International Center for Diffraction Data (ICDD): Washington, DC, USA, 1999.

57. Liss, K.-D.; Whitfield, R.E.; Xu, W.; Buslaps, T.; Yeoh, L.A.; Wu, X.; Zhang, D.; Xia, K. In situ synchrotron high-energy $\mathrm{X}$-ray diffraction analysis on phase transformations in Ti-Al alloys processed by equal-channel angular pressing. J. Synchrotron Radiat. 2009, 16, 825-834. [CrossRef] [PubMed]

58. Yan, K.; Carr, D.G.; Kabra, S.; Reid, M.; Studer, A.; Harrison, R.P.; Dippenaar, R.; Liss, K.-D. In Situ Characterization of Lattice Structure Evolution during Phase Transformation of Zr-2.5Nb. Adv. Eng. Mater. 2011, 13, 882-886. [CrossRef]

59. Dubrovinskaia, N.A.; Vennström, M.; Abrikosov, I.A.; Ahuja, R.; Ravindran, P.; Andersson, Y.; Eriksson, O.; Dmitriev, V.; Dubrovinsky, L.S. Absence of a pressure-induced structural phase transition in $\mathrm{Ti}_{3} \mathrm{Al}$ up to 25 GPa. Phys. Rev. B 2000, 63, 024106:1-024106:5. [CrossRef]

60. Asta, M.; de Fontaine, D.; van Schilfgaarde, M. First-principles study of phase stability of Ti-Al intermetallic compounds. J. Mater. Res. 1993, 8, 2554-2568. [CrossRef]

61. Ghosh, G.; Asta, M. First-principles calculation of structural energetics of Al-TM (TM = Ti, Zr, Hf) intermetallics. Acta Mater. 2005, 53, 3225-3252. [CrossRef] 
62. Liss, K.-D.; Stark, A.; Bartels, A.; Clemens, H.; Buslaps, T.; Phelan, D.; Yeoh, L.A. Directional atomic rearrangements during transformations between the alpha- and gamma-phases in titanium aluminides. Adv. Eng. Mater. 2008, 10, 389-392. [CrossRef]

63. Liss, K.-D.; Bartels, A.; Clemens, H.; Stark, A.; Buslaps, T.; Phelan, D.; Yeoh, L.A. In situ characterization of phase transformations and microstructure evolution in a gamma-TiAl based alloy. In Structural Aluminides for Elevated Temperature Applications; Kim, Y.-W., Morris, D., Yang, R., Leyens, C., Eds.; TMS (The Minerals, Metals \& Materials Society): Warrendale, PA, USA, 2008; pp. 137-144.

64. Cha, L.; Scheu, C.; Clemens, H.; Chladil, H.F.; Dehm, G.; Gerling, R.; Bartels, A. Nanometer-scaled lamellar microstructures in Ti-45Al-7.5Nb-(0; 0.5)C alloys and their influence on hardness. Intermetallics 2008, 16, 868-875. [CrossRef]

65. Srinivasarao, B.; Zhilyaev, A.P.; Muñoz-Moreno, R.; Pérez-Prado, M.T. Effect of high pressure torsion on the microstructure evolution of a gamma Ti-45Al-2Nb-2Mn-0.8 vol. \% TiB2 alloy. J. Mater. Sci., 2013, 48, 4599-4605. [CrossRef]

66. Schuster, J.C.; Palm, M. Reassessment of the binary Aluminum-Titanium phase diagram. J. Phase Equilib. Diffus. 2006, 27, 255-277. [CrossRef]

67. Anderson, D.L. Thermodynamics and Equations of State. In Theory of the Earth; Blackwell Scientific Publications: Boston, MA, USA, 1989; pp. 79-102.

68. Singh, R.S. High pressure properties of metal using various equations of state. J. Integr. Sci. Technol. 2013, 1, 48-53.

69. Birch, F. Elasticity and constitution of the Earth's interior. J. Geophys. Res. 1952, 57, 227-286. [CrossRef]

70. Murnaghan, F.D. The Compressibility of Media under Extreme Pressures. Proc. Natl. Acad. Sci. USA 1944, 30, 244-247. [CrossRef] [PubMed]

71. Dubrovinsky, L.; Dubrovinskaia, N.; Bykova, E.; Bykov, M.; Prakapenka, V.; Prescher, C.; Glazyrin, K.; Liermann, H.; Hanfland, M.; Ekholm, M.; et al. The most incompressible metal osmium at static pressures above 750 gigapascals. Nature 2015, 525, 226-229. [CrossRef] [PubMed]

72. Vinet, P.; Rose, J.H.; Ferrante, J.; Smith, J.R. Universal features of the equation of state of solids. J. Phys. Condens. Matter 1989, 1, 1941-1963. [CrossRef]

73. Nishihara, Y.; Nakajima, Y.; Akashi, A.; Tsujino, N.; Takahashi, E.; Funakoshi, K.; Higo, Y. Isothermal compression of face-centered cubic iron. Am. Mineral. 2012, 97, 1417-1420. [CrossRef]

74. Seto, Y. Seto's Home Page. Available online: http://pmsl.planet.sci.kobe-u.ac.jp/ seto (accessed on 15 April 2016).

75. Stark, A.; Rackel, M.; Tankoua, A.T.; Oehring, M.; Schell, N.; Lottermoser, L.; Schreyer, A.; Pyczak, F. In Situ High-Energy X-ray Diffraction during hot-forming of a multiphase TiAl Alloy. Metals 2015, 5, 2252-2265. [CrossRef]

76. Stark, A.; Bartels, A.; Clemens, H.; Schimansky, F. On the Formation of Ordered $\omega$-phase in High Nb Containing $\gamma$-TiAl Based Alloys. Adv. Eng. Mater. 2008, 10, 929-934. [CrossRef]

77. Rackel, M.; Stark, A.; Gabrisch, H.; Schimansky, F.; Schell, N.; Schreyer, A.; Pyczak, F. In situ synchrotron radiation measurements of orthorhombic phase formation in an advanced TiAl alloy with modulated microstructure. MRS Proc. 2015, 1760. [CrossRef]

78. Menon, E.S.K.; Fox, A.G.; Mahapatra, R. Accurate determination of the lattice parameters of $\gamma$-TiAl alloys. J. Mater. Sci. Lett. 1996, 15, 1231-1233. [CrossRef]

79. Schmoelzer, T.; Liss, K.; Kirchlechner, C.; Mayer, S.; Stark, A.; Peel, M.; Clemens, H. An in situ high-energy $\mathrm{X}$-ray diffraction study on the hot-deformation behavior of a $\beta$-phase containing TiAl alloy. Intermetallics 2013, 39, 25-33. [CrossRef]

80. Petry, W.; Heiming, A.; Trampenau, J.; Alba, M.; Herzig, C.; Schober, H.R.; Vogl, G. Phonon dispersion of the bcc phase of group-IV metals. I. bcc titanium. Phys. Rev. B 1991, 43, 10933-10947. [CrossRef]

81. Schmoelzer, T.; Liss, K.; Rester, M.; Yan, K.; Stark, A.; Reid, M.; Peel, M.; Clemens, H. Dynamic Recovery and Recrystallization during Hot-Working in an Advanced TiAl Alloy. Prakt. Metallogr. Pract. Metallogr. 2011, 48, 632-642. [CrossRef]

82. Kabra, S.; Yan, K.; Carr, D.G.; Harrison, R.P.; Dippenaar, R.J.; Reid, M.; Liss, K. Defect dynamics in polycrystalline zirconium alloy probed in situ by primary extinction of neutron diffraction. J. Appl. Phys. 2013, 113, 063513:1-063513:8. [CrossRef] 
83. Hattori, T.; Sano-Furukawa, A.; Arima, H.; Komatsu, K.; Yamada, A.; Inamura, Y.; Nakatani, T.; Seto, Y.; Nagai, T.; Utsumi, W.; et al. Design and Performance of High-Pressure PLANET Beamline at Pulsed Neutron Source at J-PARC. Nucl. Instrum. Methods Phys. Res. Sect. Accel. Spectrom. Detect. Assoc. Equip. 2015, 780, 55-67. [CrossRef]

84. Sano-Furukawa, A.; Hattori, T.; Arima, H.; Yamada, A.; Tabata, S.; Kondo, M.; Nakamura, A.; Kagi, H.; Yagi, T. Six-axis multi-anvil press for high-pressure, high-temperature neutron diffraction experiments. Rev. Sci. Instrum. 2014, 85, 113905:1-113905:8. [CrossRef] [PubMed]

85. Funakoshi, K.; Higo, Y.; Nishihara, Y. High-pressure two-dimensional angle-dispersive X-ray diffraction measurement system using a Kawai-type multianvil press at SPring-8. J. Phys. Conf. Ser. 2010, 215. [CrossRef]

C 2016 by the authors. Licensee MDPI, Basel, Switzerland. This article is an open access article distributed under the terms and conditions of the Creative Commons Attribution (CC BY) license (http://creativecommons.org/licenses/by/4.0/). 